\title{
Mechanisms of Postinfarction Electrophysiological Abnormality: Sympathetic Neural Remodeling, Electrical Remodeling and Gap Junction Remodeling
}

\author{
Guoqiang Zhong, Jinyi Li, Honghong Ke, \\ Yan He, Weiyan Xu and Yanmei Zhao \\ Department of Cardiology, The First Affiliated Hospital of Guangxi Medical University, \\ Nanning, \\ China
}

\section{Introduction}

Of various functional impairments of electrical events in the heart, ventricular arrhythmias underlie the majority of deaths in patients with left ventricular dysfunction and heart failure after myocardial ischemia and infarction. As heart failure develops, pathophysiological remodeling of cardiac function occurs at multiple levels, spanning the spectrum from molecular and subcellular changes to those occurring at the organ system levels (Jin et al., 2008).

Although advances in anti-arrhythmic agents and implantation of direct-current defibrillator have resulted in improved prevention of death due to arrhythmia in myocardial infarction, morbidity and mortality due to arrhythmias are still high in all over the world. In addition, in patients with severe congestive heart failure, ventricular arrhythmia is also a critical determinant of prognosis, because conservative anti-arrhythmia therapies are not very effective. Therapeutic strategies for arrhythmias have been focused mainly on electrophysiological aspects with little consideration of structural or cellular bases for arrhythmogenesis. Thus, the exact cellular mechanism underlying lethal arrhythmias is undetermined. Identification of arrhythmogenic substrates from viewpoints other than electrophysiological ones is essential (Takamatsu, 2008).

Despite decades of investigation, the precise mechanisms that underlie the electrophysiological abnormality remain elusive. In this chapter we therefore focus on three main issues with an emphasis on the mechanisms responsible for these adaptations: sympathetic neural remodeling, electrical remodeling and gap junction remodeling.

\section{Cardiac sympathetic neural remodeling}

\subsection{The sympathetic nervous system in the heart}

Cardiac innervation comes from both extrinsic and intrinsic sources. The extrinsic sympathetic innervation arises from the stellate ganglia and paravertebral sympathetic 
ganglia. The vagal nerves are sources of extrinsic parasympathetic nerves that innervate the heart. In addition to the extrinsic cardiac nervous system, there is also an extensive intrinsic cardiac nervous system that includes collections of ganglionated plexuses (Armour, 2010). The major neurotransmitter mediating sympathetic response is norepinephrine; of note, epinephrine release during activation is negligible (Fig 1) (Esler et al., 1990).

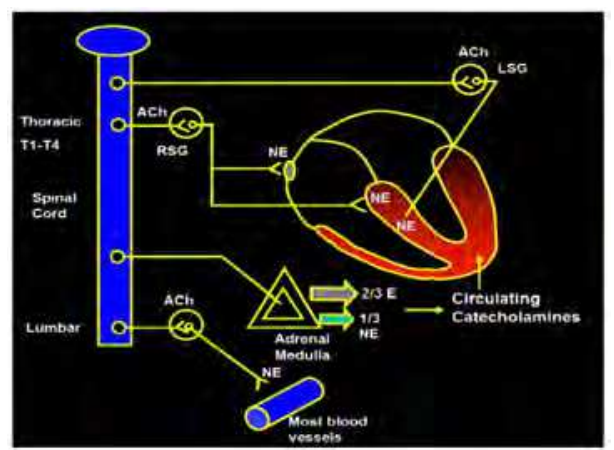

Fig. 1. Cardiac sympathetic control. NE, norepinephrine; Ach, acetylcholine; E, epinephrine (Esler et al., 1990).

Each ganglionated plexuses contains both sympathetic and parasympathetic neurons that are associated with complex synaptology. The sympathetic innervation to the ventricles follows a course along the common pulmonary artery into the plexus supplying the main left coronary artery. The sympathetic nerves are distributed to the myocardium in superficial epicardial layers. They penetrate the myocardium along with the coronary arteries (Figure 2) (Zipes, 1990). Immunocytochemical techniques have allowed investigators to stain many nerve cells and nerve tissues including the Schwann cells and autonomic nerves using different antibodies with different stains (Oki et al., 1995; Gulbenkian et al., 1993; Chow et al., 1998).

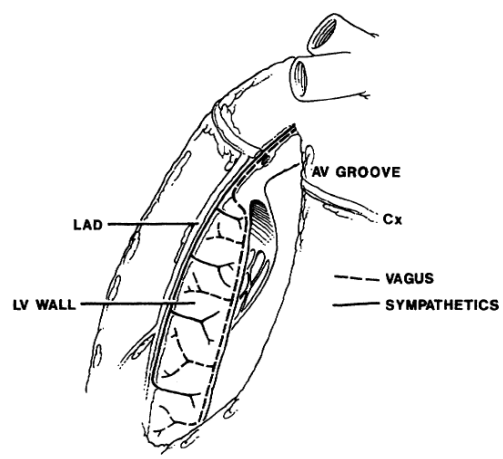

Fig. 2. Schematic of sagittal view of left ventricular wall showing pathways of vagal and sympathetic afferent and efferent nerves. Postganglionic sympathetic axons are located superficially in periadventia of coronary arteries; postganglionic vagal axons cross the atrioventricular groove in subepicardium but are located in subendocardium. $C x$, circumflex coronary artery; LAD, left ventricular descending coronary artery (Zipes, 1990). 


\subsection{Sympathetic neural remodeling after myocardial infarction}

In ischemic hearts, regional heterogeneity of sympathetic innervation usually occurs as a result of ischemia- or infarction-induced neural axons necrosis and nerve sprouting (Zipes, 1990). Sympathetic neural remodeling characterized by heterogeneous cardiac nerve sprouting and sympathetic hyperinnervation was also observed; see Figure 3 (Cao et al., 2000).

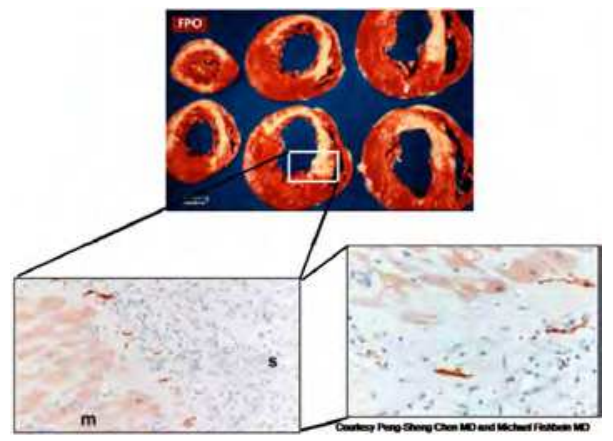

Fig. 3. Neural remodeling and nerve sprouting (Cao et al., 2000).

The density of nerve fibers immunopositive for Growth-associated protein- 43 upregulated after myocardial infarction at different periods, indicating nerve fibers undergoing sprouting activity shortly after myocardial infarction (Oh et al., 2006; Zhou et al., 2004). However, sprouting nerve fibers may regress unless nerve terminals can form synaptic contacts with target cells. Therefore, the density of growth-associated protein- 43 positive nerve fibers is a measurement for nerve sprouting activity instead of a measurement for stable innervation. Myocardial infarction induced nerve sprouting activity in both peri-infarct and remote areas. Nerve sprouting, which resulted in sympathetic (but not parasympathetic) hyperinnervation, was greater in the outer loop of the heart. The difference in the outer and inner loops started within 3 hours and persisted for 2 months after myocardial infarction (Figure 4) (Oh et al., 2006).

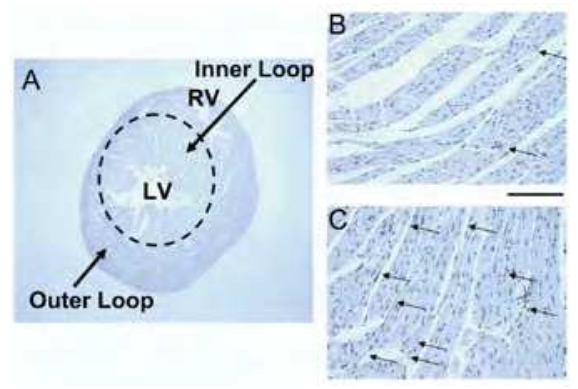

Fig. 4. Nerve fiber densities in the outer versus the inner loop of normal mouse heart. A, Cross-section of a normal mouse ventricle. The fiber orientation in the inner loop is roughly perpendicular, whereas the outer loop fibers are parallel to the circumference of the ventricles. B, C: Growth-associated protein- 43 immunopositive nerves in the inner and outer loops, respectively. More nerve fibers are present in the outer loop than the inner loop. Arrows point to brown nerve twigs $(20 \times$ objective) (Oh et al., 2006). 
Necrotic injury to the rat myocardium results in denervation followed by proliferative regeneration of schwann cells and axons (Nori et al., 1995). Abnormal patterns of neurilemma proliferation have been documented in infarsitescted human and rat hearts (Vracko, 1990, 1991). Rencently, Huazhi et al (Huazhi et al., 2010) showed that sympathetic nerve sprouting at the peri-infarct zone in infarcted hearts at 8 weeks post myocardial infarction was more excessive and heterogeneous than that in the corresponding zone in normal hearts. Excessive nerve sprouting may result in abnormal patterns of myocardial innervation and may potentially increase cardiac arrhythmia. Wei et al (Wei et al., 2004) identified a number of changes, including substantial denervation of the left ventricular and areas of apparent hyperinnervation at the border of innervated and denervated myocardium after myocardial infarction.

\subsection{Mechanisms of sympathetic neural remodeling after myocardial infarction}

The sympathetic innervation of the heart regulates cardiac function by stimulating heart rate, contractility, and conduction velocity through the release of norepinephrine and the activation of cardiac $\beta 1$-adrenergic receptors. Sympathetic innervation of the heart is sculpted during development by chemoattractive and chemorepulsive factors (Ieda et al., 2007). For example, nerve growth factor supports sympathetic neuron survival and promotes cardiac axon outgrowth during development (Crowley et al., 1994), whereas the chemorepulsive factorsemaphorin $3 \mathrm{a}$ (Sema3a) attenuates sympathetic axon extension in the heart (Ieda et al., 2007) and in the peripheral vasculature (Long et al., 2009).

The nerve fiber regeneration process is triggered by up-regulation of nerve growth factor or other neurotrophic factor genes in the non-neuronal cells around the site of injury. Upregulation of nerve growth factor was more prominent in the area near the infarct than in the area remote to the infarct (Oh et al., 2006). Nerve growth factor mRNA was significantly up-regulated within 3 hours after myocardial infarction and persisted for 1 month in both the infarcted myocardium and the noninfarcted left ventricular free wall (Oh et al., 2006; Zhou et al., 2004).

Neurotrophins such as nerve growth factor act through two distinct types of receptors: tropomyosin-related tyrosine kinase (Trk) receptors and the lower-affinity p75 neurotrophin receptor (p75NTR) (Kuruvilla et al., 2004; Kaplan \& Miller, 2003). Nerve growth factor acts through TrkA to promote the extension of sympathetic axons into the heart (Kuruvilla et al., 2004), whereas p75NTR modulates signaling by coreceptors that can either stimulate or inhibit axon outgrowth (Kaplan \& Miller, 2003). p75NTR has a great functional impact on the cardiovascular system and cardiac rhythm stability (Christina et al., 2010), which were particularly relevant to myocardial infarction and heart failure where heterogeneous sympathetic innervation was correlated with altered neurotrophin expression and the development of ventricular arrhythmias (Rubart \& Zipes, 2005).

In addition to nerve growth factor, other neurotrophic factors are also up-regulated after myocardial infarction. For example, Leukemia inhibitory factor protein was increased by $40 \%$ at 48 hours after myocardial infarction in mice (Fuchs et al., 2003). IL-1a was increased after myocardial infarction, primarily at peri-infarct sites. And IL-1, IL-1 $\beta$, and IL-6 were increased at only one time point after myocardial infarction (Oh et al., 2006; Nian et al., 2004). IL-6 mRNA was induced in myocytes at the viable border zone in dogs subjected to ischemia-reperfusion (Gwechenberger et al., 1999). Table 1 describes detailly neurotrophic factors gene expression in the myocardium after myocardial infarction. 


\begin{tabular}{|c|c|c|c|c|c|c|c|c|c|c|}
\hline & \multicolumn{5}{|c|}{ Peri-infarct } & \multicolumn{5}{|c|}{ Remote } \\
\hline & 3 hours & 3 days & 1 week & 1 month & 2 months & 3 hours & 3 days & 1 week & 1 month & 2 months \\
\hline NGF- $\alpha$ & 1.97 & 2.00 & 0.70 & 0.80 & 1.35 & 9.64 & 2.57 & 3.42 & 1.18 & 11.03 \\
\hline NGF- $\beta$ & $5.63(2.14)$ & $8.02(2.40)$ & $0.69(1.79)$ & $0.81(1.39)$ & $4.15(1.40)$ & 1.98 & 2.26 & 0.95 & 0.28 & 0.39 \\
\hline NGF- $\gamma$ & 5.31 & 1.91 & 1.42 & 1.59 & 0.57 & 1.09 & 1.74 & 0.92 & 3.48 & 4.47 \\
\hline BDNF & 1.54 & 1.93 & 1.89 & 1.22 & 1.22 & 1.34 & 0.67 & 0.72 & 0.30 & 0.67 \\
\hline NT-3 & 1.10 & 0.38 & 0.27 & 0.24 & 0.46 & 0.78 & 0.38 & 0.36 & 0.78 & 0.14 \\
\hline FGF & 0.37 & 0.09 & 0.07 & 0.23 & 0.14 & 0.15 & 0.28 & 0.10 & 0.15 & 2.46 \\
\hline EGF & 2.12 & 0.48 & 0.39 & 3.33 & 0.62 & 0.64 & 0.08 & 0.09 & 0.09 & 0.24 \\
\hline IGF $1-1$ & 1.53 & 1.20 & 0.94 & 0.96 & 0.95 & 0.98 & 0.54 & 0.55 & 0.42 & 0.67 \\
\hline IGF $1-2$ & 3.72 & 8.55 & $8.18(5.80)$ & 3.78 & $3.47(4.04)$ & 2.15 & 7.54 & 4.68 & 1.50 & 2.31 \\
\hline IGF $2-1$ & 16.86 & 0.71 & 0.43 & 0.71 & 0.48 & 0.98 & 1.09 & 2.82 & 1.28 & 4.65 \\
\hline IGF $2-2$ & 1.40 & 1.12 & 1.18 & 0.76 & 0.75 & 0.85 & 0.65 & 0.42 & 0.34 & 0.51 \\
\hline GDNF & 1.15 & 0.79 & 0.92 & 0.69 & 1.64 & 1.01 & 0.27 & 0.86 & 0.53 & 0.85 \\
\hline LIF & $4.70(1.01)$ & $6.43(4.23)$ & $3.75(2.06)$ & $2.93(1.15)$ & $6.28(2.93)$ & 1.17 & 3.36 & 0.98 & 0.89 & 32.1 \\
\hline TGF- $\alpha$ & 0.63 & 1.75 & 0.65 & 0.82 & 2.64 & 1.05 & 0.56 & 1.30 & 0.51 & 3.77 \\
\hline TGF- $\beta_{1}$ & 1.48 & 1.05 & 0.77 & 0.91 & 0.88 & 0.50 & 0.91 & 0.79 & 0.26 & 0.59 \\
\hline TGF- $\beta_{2}$ & 2.67 & 3.35 & 1.15 & 2.27 & 0.24 & 1.61 & 0.40 & 1.74 & 0.22 & 7.01 \\
\hline TGF- $\beta_{3}$ & 3.25 & 4.26 & $14.46(13.27)$ & 7.23 & $3.34(2.71)$ & 3.85 & 4.07 & 2.69 & 1.98 & 5.84 \\
\hline $\mathrm{IL}-1 \alpha^{3}$ & 3.50 & 4.03 & $3.33(2.54)$ & 2.55 & $3.60(5.11)$ & 0.85 & 1.48 & 1.09 & 0.63 & 1.41 \\
\hline IL- $1 \beta$ & 1.20 & 1.51 & 3.45 & 2.03 & 1.45 & 0.91 & 1.23 & 0.93 & 0.43 & 0.51 \\
\hline IL-6 & 4.92 & 0.42 & 1.03 & 0.38 & 0.14 & 65.34 & 2.01 & 3.13 & 0.36 & 1.15 \\
\hline TNF- $\alpha$ & 2.35 & 1.02 & 1.07 & 1.33 & 0.84 & 1.45 & 1.78 & 1.39 & 0.97 & 2.02 \\
\hline TNF- $\beta$ & 0.73 & 1.27 & 1.47 & 0.36 & 2.89 & 1.41 & 1.09 & 0.43 & 0.75 & 2.11 \\
\hline
\end{tabular}

Table 1. Neurotrophic factors gene expression in the myocardium after myocardial infarction Numbers indicate ratio to normal control. Bold numbers indicate those $>3 \times$ of control in at least two consecutive time points. Bold numbers in parentheses are obtained with quantitative reverse-transcriptase polymerase chain reaction. Other numbers are obtained using DNA microarray. $\mathrm{BDNF}=$ brain-derived neurotrophic factor; EGF = epidermal growth factor; FGF = fibroblast growth factor; GDNF = glial cell-derived neurotrophic factor; IGF = insulin-like growth factor; IL = interleukin; LIF = leukemia inhibitory factor; NT-3 = neutrophin-3; NGF, nerve growth factor; TGF = transforming growth factor; TNF = tumor necrosis factor (Oh et al., 2006).

Increase of neurotrophic factors sometimes can be injurious. Thus, both exogenous and endogenous nerve growth factor can induce cardiac nerve sprouting, but they also can increase the incidence of ventricular arrhythmias and sudden death in canine models (Cao et al., 2000a). Increased neurotrophic factor expression and heterogeneous innervation also could induce side effects that contribute to the increased risk for sudden death after myocardial infarction (Luisi et al., 2002; Canty et al., 2004).

\subsection{The interaction between sympathetic neural remodeling and electrical remodeling}

Regional heterogeneity of sympathetic innervation is also closely related to electrical inhomogeneity. Previous study revealed that electrical heterogeneity is exacerbated after initial nerve injury by sympathetic nerve sprouting and subsequent regional myocardial hyperinnervation (Figure 6) (Rubart \& Zipes, 2005). The enhanced spatial inhomogeneity in cardiac sympathetic innervation could amplify the spatial inhomogeneity of these electrophysiological properties and therefore facilitate the initiation of ventricular arrhythmias (Cao et al., 2000b).

Nerve growth factor overexpression and nerve sprouting affected the expressions and functions of certain potassium channels and thus increases the susceptibility to ventricular tachyarrhythmia. Nerve sprouting suppressed the expressions and functions of myocardial transient outward current $\left(\mathrm{I}_{\mathrm{to}}\right)$ and inward rectifier current $\left(\mathrm{I}_{\mathrm{K} 1}\right)$ channels. Myocardial necrotic injury plus intensified sympathetic nerve sprouting further decreased Kir2.1 expression and $\mathrm{I}_{\mathrm{K} 1}$ current density. All of these changes affected the repolarization of myocardial cells and hence increased the vulnerability to ventricular arrhythmia (Ren et al., 2008). 


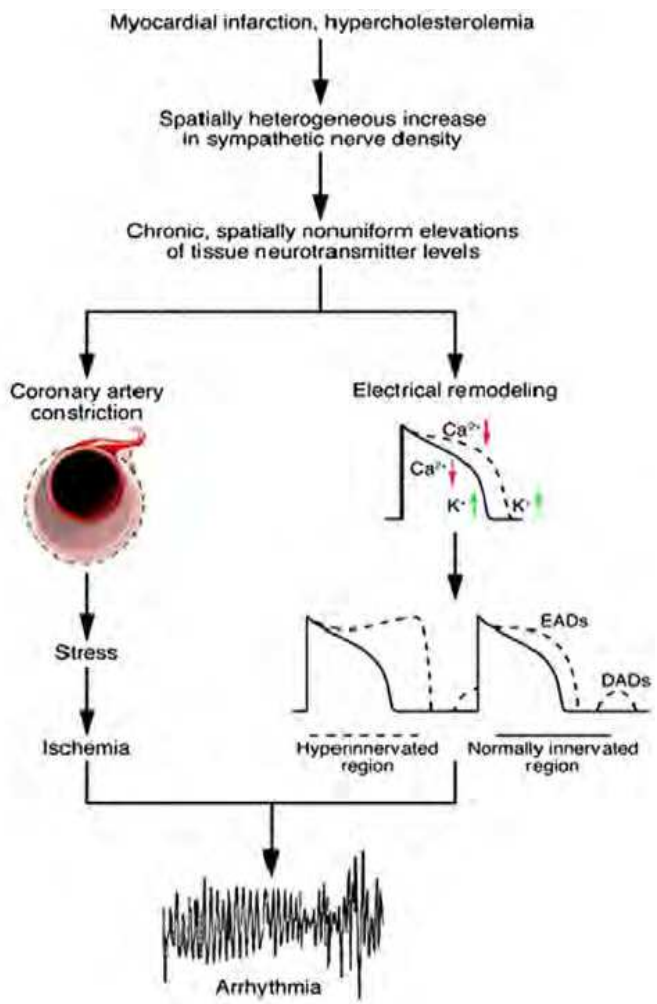

Fig. 6. Factors contributing to arrhythmogenesis in hearts with heterogeneous sympathetic innervation (Rubart \& Zipes, 2005).

Besides, the coexistence of sympathetic denervation zones (infarct zones), sympathetic reinnervation zones (ischemic zones) and sympathetic normal zones in the ischemic heart could increase the heterogeneity of electrical communication which is facilitative to the abnormality of cardiac autorhythmicity and triggered activity. Sympathetic neural remodeling can raises the norepinephrine concentration, which encourage the early afterdepolarization (EAD) and delayed afterdepolarization (DAD) by affect the calcium influx and repolarization potassium current, and then trigger arrhythmia. Neurotransmitters such as norepinephrine can cause focal vasoconstriction and myocardial ischemia which is facilitative to the arrhythmogenesis.

\subsection{Relationship between sympathetic neural remodeling and ventricular arrhythmia}

The initiation of lethal arrhythmias needs a substrate and a trigger. Myocardial remodeling (structural and/or functional) is considered the substrate. In recent years, the concept "cardiac nerve remodeling" and its potentiality as a trigger for lethal arrhythmia have entered the scope of arrhythmia research (Ren et al., 2008). Abnormally increased post-injury sympathetic nerve density may be in part responsible for the occurrence of ventricular arrhythmia and sudden cardiac death in patients with severe heart failure (Cao et al., 2000b). Cardiac nerve sprouts detering occured after myocardial infarction even without exogenous nerve growth factor. 
Infusion of nerve growth factor accelerated and intensified the magnitude of nerve sprouting, resulting in a high incidence of sudden cardiac death (Cao et al., 2000a).

The left stellate ganglion is known to be important in cardiac arrhythmogenesis (Schwartz \& Stone, 1980). Left cardiac sympathetic denervation, including left stellate ganglion resection, decreases the incidence of ventricular arrhythmia in patients with myocardial infarction (Schwartz et al., 1992). Increased sympathetic tone is important in the generation of ventricular arrhythmia and sudden cardiac death (Rubart \& Zipes, 2005). In dogs with both complete atrioventricular block and myocardial infarction, high-amplitude spiky discharges frequently cause premature ventricular contractions or even ventricular tachycardia (Figure 7). These findings suggest that high-amplitude spiky discharges is highly arrhythmogenic in diseased hearts. However, because high-amplitude spiky discharges is also present in normal hearts, the presence of these types of discharge by itself is not pathological (Zhou S, et al., 2008).

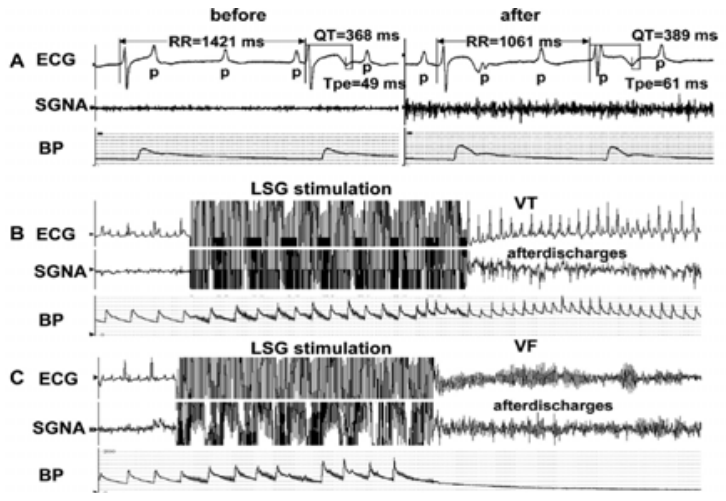

Fig. 7. A, Electrical stimulation of left stellate ganglion lengthened the corrected QT (QTc) from 325 to $402 \mathrm{~ms}$ and the corrected Tpe (Tpec) from 45 to $82 \mathrm{~ms}$ (at $10 \mathrm{~mA}$ ). B, Left stellate ganglion stimulation induced ventricular tachycardia (VT); C, ventricular fibrillation (VF) in the experimental group. Afterdischarges were present in left stellate ganglion recordings after electrical stimulation. $\mathrm{BP}=$ blood pressure; SGNA = stellate ganglion nerve activity (Zhou S, et al., 2008).

\subsection{Therapeutic implications of sympathetic neural remodeling after myocardial infarction}

As sympathetic tone was known to be increased in cardiomyopathy patients, interventions that aim to reduce sympathetic tone could reduce the risk of sudden cardiac death and ventricular tachyarrhythmias (Fig 8 , Marmar \& Kalyanam, 2008).

Selective sympathetic blockade was an effective theraty, which was applied in animal models and human during myocardial ischemia (Issa et al., 2005; Nademanee et al., 2000). In a canine model, intrathecal clonidine, when delivered via a catheter at T2-T4 spinal segments, significantly reduced the occurrence of ventricular tachycardia and fibrillation during transient myocardial ischemia (Issa et al., 2005). Electrical storm, defined as recurrent multiple ventricular fibrillation (VF) episodes, often occurs in patients with recent myocardial infarction. Sympathetic blockade was proved to be superior to the antiarrhythmic therapy in treating electrical storm patients, and sympathetic blockade - not class 1 antiarrhythmic drugs - should be the treatment of choice for electrical storm 
(Nademanee et al., 2000). Successful treatment of recurrent ventricular tachycardia, refractory to antiarrhythmic therapy, can be achieved by neuraxial modulation at the level of the spinal cord. The benefit of thoracic epicardial anesthesia was reported in a patient with ischemic cardiomyopathy and recurrent ventricular arrhythmia refractory to intubation and sedation, with the use of $0.25 \%$ Bupicavaine at T1-T2 interspace, reducing the number of ICD shocks from 86 in 48 hours to zero (Mahajan et al., 2005).

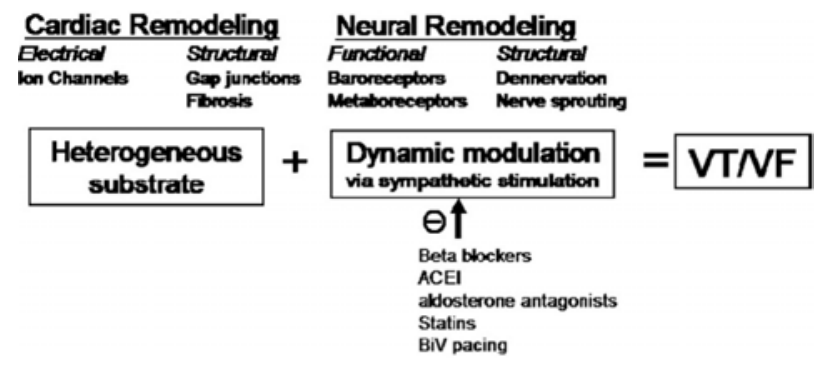

Fig. 8. Structural and functional basis of ventricular tachycardia and fibrillation (Marmar \& Kalyanam, 2008).

$\beta$-blockers, angiotensin-converting enzyme inhibitors, angiotensin receptor blockers, aldosterone antagonists (Cittadini et al., 2003), statins (Gao et al., 2005), and fish oil have been shown to decrease risk of sudden cardiac death in ischemic cardiomyopathy and significantly improve mortality through modulating the autonomic nervous system to decrease sympathetic tone (Marmar \& Kalyanam,2008). In a recent study, carvedilol ameliorated electrical remodeling at peri-infarct zones after myocardial infarction by improving the spatial distribution of the sympathetic nerve reinnervation (Huazhi et al., 2010). Moreover, attenuation of oxidative stress and inflammatory response after resveratrol treatment, a naturally occurring compound, significantly inhibited nerve growth factor expression, and protected against sympathetic neural remodeling (Ping et al., 2010). Ghrelin, a novel growth hormone-releasing peptide, which was showed to inhibite neural remodeling in rats with myocardial infarction, likely mediated through nerve growth factor suppression, might be used as a new potential way to treat and prevent sudden cardiac death after myocardial infarction (Ming-Jie et al., 2009).

\section{Myocardial electrical remodelling}

\subsection{The cardiac action potential}

The normal sequence and synchronous contraction of the atria and ventricles require the rapid activation of groups of cardiac cells. An activation mechanism must enable rapid changes in heart rate and also respond to the changes in autonomic tone. The propagating cardiac action potential fulfils these roles. The action potential is a key determinant of cardiac electrical activity and is shaped by underlying ionic currents and transporters (Nerbonne \& Kass 2005). A schematic representation of a cardiac action potential and the principal currents involved in its various phases are shown in Figure 9A (Nattel \& Carlsson 2006). The action potentials of pacemaker cells in the sinoatrial (SA) and atrioventricular (AV) nodes are significantly different from those in working myocardium. Figure 9B depicts action potential characteristics in different regions of the heart (Michael et al., 2009). 
The average duration of the ventricular action potential duration is reflected in the QT interval in the ECG. Factors that prolong the action potential duration (eg, a decrease in outward $\mathrm{K}^{+}$ currents or an increase in inward late $\mathrm{Na}^{+}$current) prolong the action potential duration and the QT interval in the ECG. The QT interval of males and females is equal during early childhood. However, at puberty the interval of males shortens (Rautaharju et al., 1992).
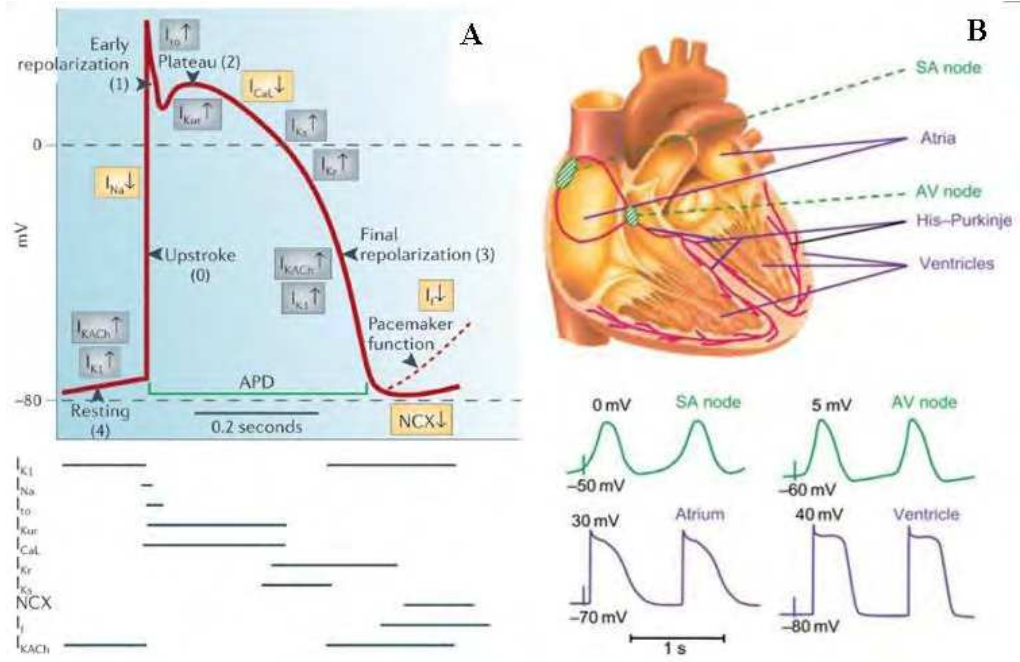

Fig. 9. A, Membrane currents that generate the normal action potential duration. Resting (4), upstroke (0), early repolarization (1), plateau (2), and final repolarization are the 5 phases of the action potential. A decline of potential at the end of phase 3 in pacemaker cells, such as the sinus node, is shown as a broken line. The inward currents, $\mathrm{I}_{\mathrm{Na}}, \mathrm{I}_{\mathrm{Ca}}$, and $\mathrm{I}_{\mathrm{f}}$, are shown in yellow boxes; the sodium-calcium exchanger (NCX) is also shown in yellow. It is electrogenic and may generate inward or outward current. $\mathrm{I}_{\mathrm{KAch}}, \mathrm{I}_{\mathrm{K} 1}, \mathrm{I}_{\mathrm{to}}, \mathrm{I}_{\mathrm{Kur}}, \mathrm{I}_{\mathrm{Kr}}$, and $\mathrm{I}_{\mathrm{Ks}}$ are shown in gray boxes. The action potential duration is approximately $200 \mathrm{~ms}$. B, Various specialized tissues in the heart and typical corresponding action potentials. The short vertical lines indicate the time of onset of activity in the sinus atrial node for one beat. Green, slow-channel tissue (nodes); violet, fast-channel tissues (Nattel \& Carlsson 2006).

\subsection{General properties of ion channels}

Ion channels have two fundamental properties, ion permeation and gating (Hille, 1978). Ion permeation describes the movement through the open channel. The selective permeability of ion channels to specific ions is a basis of classification of ion channels $\left(\mathrm{eg}, \mathrm{Na}^{+}, \mathrm{K}^{+}\right.$, and $\mathrm{Ca}^{2+}$ channels). Size, valency, and hydration energy are important determinants of selectivity (Augustus, 2009). Ion channels provide multiple binding sites for ions as they traverse the membrane. Like an enzyme-substrate interaction, the binding of the permeating ion is saturable. Most ion channels are singly occupied during permeation; certain $\mathrm{K}^{+}$channels may be multiply occupied (Augustus, 2009).

Gating is the mechanism of opening and closing of ion channels and is their second major property. Ion channels are also subclassified by their mechanism of gating: voltagedependent, ligand-dependent, and mechano-sensitive gating. Voltage-gated ion 
channels change their conductance in response to variations in membrane potential. Voltage-dependent gating is the commonest mechanism of gating observed in ion channels. A majority of ion channels open in response to depolarization. The pacemaker current channel ( $\mathrm{I}_{\mathrm{f}}$ channel) opens in response to membrane hyperpolarization. The steepness of the voltage dependence of opening or activation varies between channels (Hille, 1978).

Ion channels have two mechanisms of closure. Certain channels like the $\mathrm{Na}^{+}$and $\mathrm{Ca}^{2+}$ channels enters a closed inactivated state during maintained depolarization. To regain their ability to open, the channel must undergo a recovery process at hyperpolarized potentials. The inactivated state may also be accessed from the closed state. Inactivation is the basis for refractoriness in cardiac muscle and is fundamental for the prevention of premature reexcitation (Hille, 1978; Leblanc \& Hume, 1990).

Ligand-dependent gating is the second major gating mechanism of cardiac ion channels. The acetylcholine (Ach)-activated $\mathrm{K}^{+}$channel, an inward-rectifying $\mathrm{K}^{+}$channel ( $\mathrm{I}_{\mathrm{KAch}}$ ), is one of this class. $\mathrm{I}_{\mathrm{KAch}}$ channels are most abundant in the atria and the sinus atrial and atrioventricular nodes. The ATP-sensitive $\mathrm{K}^{+}$channel, also termed the ADP-activated $\mathrm{K}^{+}$ channel, is a ligand-gated channel distributed abundantly in all regions of the heart. Energy depletion during ischemia increases the $[\mathrm{ADP}] /[\mathrm{ATP}]$ ratio, activates $\mathrm{I}_{\mathrm{KATP}}$, and abbreviates the action potential. The abbreviated action potential results in less force generation and may be cardioprotective. This channel also plays a central role in ischemic preconditioning (Hille, 1978).

\subsection{Significance and arrhythmic consequences of lonic currents remodeling associated with myocardial infarction}

Myocardial infarction refers to the death of cardiac tissue, most often caused by critical decreases in coronary artery blood flow induced by obstructive coronary artery disease. Several mechanisms, including reentry and triggered activity due to early and delayed afterdepolarizations, contribute to ventricular tachyarrhythmia (Janse \& Wit, 1989; Qin et al., 1996). Remodeling of ion-channel and transport processes cause important changes in cellular electrical activity and impulse propagation over days and weeks following acute infarction (Friedman et al., 1975; Spear et al., 1977).

Generally, by $24-48 \mathrm{~h}$ after total coronary artery occlusion the action potentials and maximal action potential upstroke velocity (Vmax) decreased, as well as an increase in total time of repolarization. On the other hand, the cells of the epicardial border zone of the canine infarction model show a reduction in Vmax, and a shortening and triangularization of the action potential by 5 days after total artery occlusion. By 14 days post occlusion further shortening of the action potential occurs. Then by the time of the healed infarct ( 2 months), action potential voltage profiles have returned to nearly normal suggesting the presence of a process that might be termed 'reverse remodeling' (Figure 10) (Ursell et al., 1985). We found that the PR, QRS, QT and QTc intervals in myocardial infarction mice were significantly longer than normal mice after 4, 8, and 12 weeks (LI et al., 2009c).

These abnormalities cause severe conduction disturbances that strongly promote reentry. A particularly important arrhythmia mechanism is anisotropic reentry in the peri-infarction border zone (Dillon et al., 1988; Restivo et al., 1990). Acute myocardial infarction causes longer term (remodeling) changes over days to weeks, as well as important very early (within minutes to hours) functionally based ion-channel abnormalities. Figure 11 illustrates how different forms of ionchannel remodeling contribute to anisotropic reentry in the presence of a healed myocardial infarction (Nattel S et al., 2007). 

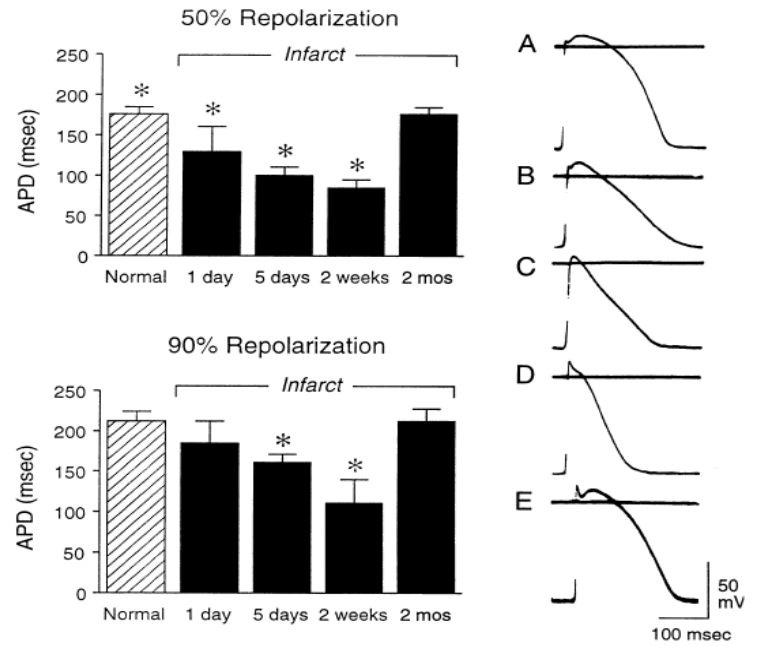

Fig. 10. Changes in action potential duration measured to 50\% (above left) and $90 \%$ repolarization (below left) of epicardial muscle fibers with increasing time after coronary artery occlusion. Asterisks denote values significantly different from control. At the right are shown representative transmembrane potential recordings; A, normal; B, 1 day; C, 5 days; D, 2 weeks; E, 2 months. Note that action potentials in the 1- and 5-day-old infarcts show loss of the plateau phase during repolarization. Action potential duration is decreased more in 5-day-old than in 1-day-old infarcts (Ursell et al., 1985).

\subsection{Alterations in $\mathrm{K}^{+}$currents}

Cardiac $\mathrm{K}^{+}$channels fall into three broad categories: Voltagegated ( $\mathrm{I}_{\mathrm{to}}, \mathrm{I}_{\mathrm{Kur}}, \mathrm{I}_{\mathrm{Kr}}$, and $\left.\mathrm{I}_{\mathrm{Ks}}\right)$, inward rectifier channels $\left(\mathrm{I}_{\mathrm{K} 1}, \mathrm{I}_{\mathrm{KAch}}\right.$, and $\left.\mathrm{I}_{\mathrm{KATP}}\right)$, and the background $\mathrm{K}^{+}$currents (TASK-1, TWIK-1/2). Voltage-gated $\mathrm{K}^{+}$channels consist of principal $\alpha$-subunits and multiple $\beta$ subunits. The channel functional units also include the complementary proteins $\mathrm{K}_{\mathrm{V}}$-channel associated protein, $\mathrm{KChAP}$, and the $\mathrm{K}_{\mathrm{V}}$ channel interacting protein, KChIP. The major subfamilies of $\alpha$-subunits include $\mathrm{K}_{V} \mathrm{~N} . x$ ( $\mathrm{n}=1$ to 4 ), the HERG channel (gene KCNH2), and $\mathrm{K}_{\mathrm{v}}$ LQT1 (gene KCNQ1). They are important in generating outward current in the heart (Augustus, 2009). Myocardial infarction causes substantial changes in $\mathrm{K}^{+}$current expression, density, and function (Janse \& Wit, 1989).

\subsubsection{Changed $\mathrm{K}^{+}$current function in surviving border-zone cells}

A variety of $\mathrm{K}^{+}$currents are downregulated in border-zone cells. Background $\mathrm{K}^{+}$ conductance is reduced in surviving canine subendocardial Purkinje fibers (Boyden et al., 1989), due to reduced $I_{K 1}$ and altered delayed-rectifier currents (Pinto \& Boyden, 1998). Border-zone left ventricular cardiomyocytes show reduced $I_{\text {to }}$ (Lue \& Boyden, 1992). $I_{\text {to }}$ decreases are most prominent within days of acute infarction and tend to resolve over the subsequent 2 months (Dun et al., 2004). The expression of subunits encoding $I_{K r}(E R G)$ and $\mathrm{I}_{\mathrm{Ks}}(\mathrm{KvLQT1}$ and $\operatorname{minK}$ ) is downregulated in 2-day postinfarction border-zone cells (Dun \& Boyden, 2005; Jiang et al., 2000). Overall, the multiple forms of $\mathrm{K}^{+}$-channel dysfunction postinfarction impair repolarization and lead to early afterdepolarizations. 


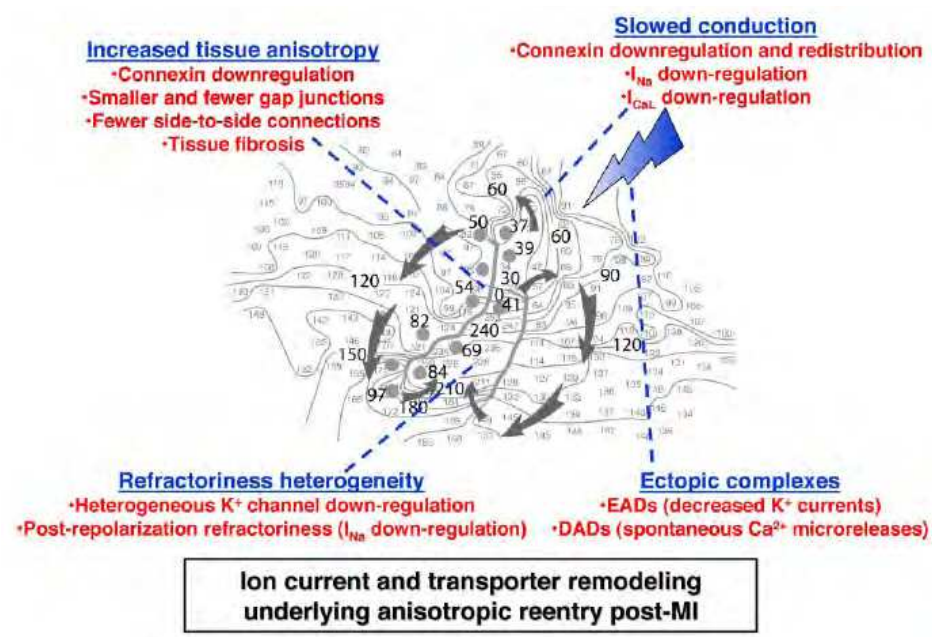

Fig. 11. Contributors to anisotropic reentry in myocardial infarction. A principal mechanism underlying potentially lethal ventricular tachyarrhythmias post-myocardial infarction is anisotropic reentry, represented schematically by the black activation map in the central part of the figure (Peters et al., 1997). The numbers indicated on the map are times of electrical activation, and the curved lines (isochrones) indicate zones of tissue activated within $10 \mathrm{~ms}$ of each other. Crowded isochrones denote very slow conduction. Thicker black lines show lines of functional conduction block parallel to fiber orientation, due to the impaired transverse conduction (increased anisotropy) post-myocardial infarction. The impulse travels slowly in two parallel streams (thick arrows) around the lines of block, which come together to conduct through the central corridor (thinner arrows) of the reentrant pathway. The ways in which ion-channel remodeling post-myocardial infarction lead to this arrhythmia mechanism are indicated by the red points, organized into groups of dysfunction categories (blue underlined headings). Increased tissue anisotropy, which causes the unidirectional block needed for reentry initiation, arises because of connexin downregulation, reduced gap junction number and size, fewer side-to-side connections, and tissue fibrosis around muscle bundles. Unidirectional block is also favored by refractoriness heterogeneity due to spatially heterogeneous $\mathrm{K}^{+}$channel downregulation coupled with postrepolarization refractoriness. Slowed conduction, which allows enough time for the proximal part of the central corridor to recover excitability when the reentering impulse returns, is caused by connexin downregulation, $\mathrm{I}_{\mathrm{Na}}$ decreases, and reduced $\mathrm{I}_{\mathrm{CaL}}\left(\mathrm{I}_{\mathrm{CaL}}\right.$ is particularly important for conduction in conditions of impaired coupling). Finally, the ectopic complexes needed to engage spatially variable refractoriness and initiate reentry are provided by early afterdepolarizations promoted by $\mathrm{K}^{+}$current downregulation and delayed afterdepolarizations caused by spontaneous diastolic $\mathrm{Ca}^{2+}$ releases (Nattel S et al., 2007).

\subsubsection{Changes in $\mathrm{K}^{+}$currents in normal zones of hearts with prior myocardial infarction}

Action potential duration increases and ventricular arrhythmias are features of normal-zone tissues from postinfarction rat (Perrier et al., 2004) and rabbit (Liu et al., 2004) hearts. Both reentries associated with spatial refractoriness heterogeneity and triggered activity is 
involved (Liu et al., 2004). Decreases in $\mathrm{I}_{\mathrm{to}}, \mathrm{I}_{\mathrm{K} 1}$, and total delayed-rectifier current $\left(\mathrm{I}_{\mathrm{K}}\right)$ occur in rabbit hearts (Liu et al., 2004). In rats, $I_{\text {to }}$ decreases correlate most closely with downregulation of Kv4.2 subunits (Perrier et al., 2004). There may be compensatory upregulation of Kv1.4 subunits (Kaprielian et al., 2002), although downregulation of Kv1.4 has also been reported (Gidh-Jain et al., 1996). Decreases in rat $\mathrm{I}_{\mathrm{K}}$ correlate with downregulation of the putative a-subunit Kv2.1 (Huang et al., 2001b). The effects of postinfarction remodeling on spatial dispersion of electrophysiological properties in noninfarcted tissues are controversial, with one study showing increases in dispersion (Huang et al., 2001b) and another decreased spatial heterogeneity (Kaprielian et al., 2002).

\subsection{Alterations in $\mathrm{Ca}^{2+}$ currents and cellular $\mathrm{Ca}^{2+}$ handling}

Calcium ions are the principal intracellular signaling ions. They regulate excitationcontraction coupling, secretion, and the activity of many enzymes and ion channels. $\left[\mathrm{Ca}^{2+}\right]_{\mathrm{i}}$ is highly regulated despite its marked fluctuation between systole and diastole. Calcium channels are the principal portal of entry of calcium into the cells; a system of intracellular storage sites, and transporters such as the sodium-calcium exchanger, also play important roles in $\left[\mathrm{Ca}^{2+}\right]_{\mathrm{i}}$ regulation. In cardiac muscle, two types of $\mathrm{Ca}^{2+}$ channels, the L- (low threshold type) and T-type (transient-type), transport $\mathrm{Ca}^{2+}$ into the cells. The L-type channel is found in all cardiac cell types. The T-type channel is found principally in pacemaker, atrial, and Purkinje cells. The unqualified descriptor $\mathrm{Ca}^{2+}$ channel refers to the L-type channel. Table 2 contrasts the properties of the two types of channels (Augustus, 2009). Changes in $\mathrm{Ca}^{2+}$ handling contribute importantly to arrhythmogenesis postinfarction.

\begin{tabular}{lcc}
\hline & L-Type & T-Type \\
\hline $\begin{array}{l}\text { Activation } \\
\text { Range }\end{array}$ & Low Em $(\approx-30 \mathrm{mV})$ & High Em $(\approx-60 \mathrm{mV})$ \\
$\begin{array}{l}\text { Inactivation } \\
\text { Range }\end{array}$ & Low Em $\approx-40 \mathrm{mV})$ & Hyperpolarized \\
Voltage dependence & Slow & Fast \\
{$\left[\mathrm{Ca}^{2+}\right]_{1}$ dependent } & Yes & No \\
Pharmacologic sensitivity & & \\
Dihydropyridnes & Yes & No \\
$\mathrm{Cd}$ & High & Low \\
$\mathrm{N}_{\mathrm{i}}$ & Low & High \\
Isoproternol & Yes & No \\
\hline
\end{tabular}

Table 2. A comparisons of the L-type and T-type Ca2+ channels (Augustus, 2009).

\subsubsection{Changes in $\mathrm{Ca}^{2+}$ current}

$\mathrm{I}_{\mathrm{CaL}}$ is diminished in border-zone cells of dogs (Dun et al., 2004), sheep (Kim et al., 2002), cats (Pinto et al., 1997), and rabbits (Litwin et al., 2000). I $\mathrm{CaL}_{\mathrm{L}}$ kinetic properties also change, with slowed recovery (Dun et al., 2004) and hyperpolarizing shifts in inactivation voltage dependence (Pinto et al., 1997). The $\mathrm{I}_{\mathrm{CaL}}$ response to dihydropyridine agonists ( $\mathrm{Pu}$ et al., 1999) and tyrosine kinase inhibitors (Yagi \& Boyden, 2002) is preserved in the border zone. T-type $\mathrm{Ca}^{2+}$ current $\left(\mathrm{I}_{\mathrm{CaT}}\right)$ varies over time, being unchanged 5 days postinfarction (Aggarwal \& Boyden, 1995) and increasing thereafter (Dun et al., 2004). In surviving subendocardial Purkinje cells, both $\mathrm{I}_{\mathrm{CaL}}$ and $\mathrm{I}_{\mathrm{CaT}}$ are reduced (Boyden \& Pinto, 1994). 


\subsubsection{Changes in cellular $\mathrm{Ca}^{2+}$ handling}

$\mathrm{Ca}^{2+}$ transients in border-zone cells are decreased in amplitude and show slowed recovery and decay (Kim et al., 2002). SERCA2A, the sarcoplasmic reticulum $\mathrm{Ca}^{2+} \mathrm{ATPase}$, is downregulated (Kim et al., 2002). The diminished and slowed $\mathrm{Ca}^{2+}$ transients are due to impaired spatial coordination of quantal $\mathrm{Ca}^{2+}$ releases, or sparks (Litwin et al., 2000). $\mathrm{Na}^{+-}$ $\mathrm{Ca}^{2+}$ exchange function is unaltered, and action potential abnormalities are not responsible for $\mathrm{Ca}^{2+}$ handling abnormalities (Pu et al., 2000). Surviving subendocardial Purkinje cells show marked abnormalities in subcellular $\mathrm{Ca}^{2+}$ release events, with spontaneous and spatiotemporally nonuniform microreleases that can trigger arrhythmic episodes (Boyden et al., 2003). Drugs that suppress $\mathrm{Ca}^{2+}$ microreleases by either inhibiting sarcoplasmic reticulum $\mathrm{Ca}^{2+}$ release channels or inositol trisphosphate receptors may constitute a novel antiarrhythmic approach postinfarction (Boyden et al., 2004).

\subsection{Alterations in $\mathrm{Na}^{+}$current}

The human cardiac sodium channel $\mathrm{hNav} 1.5$ is a member of the family of voltage-gated sodium channels ( $\mathrm{hNa}_{\mathrm{v}} 1$ to 9). The channel consists of a primary a-and multiple secondary $\beta$-subunits. The sodium channel consists of 4 homologous domains, DI through DIV (Noda et al., 1984) arranged in a 4-fold circular symmetry to form the channel (Figure 12) (Herbert \& Chahine, 2006).

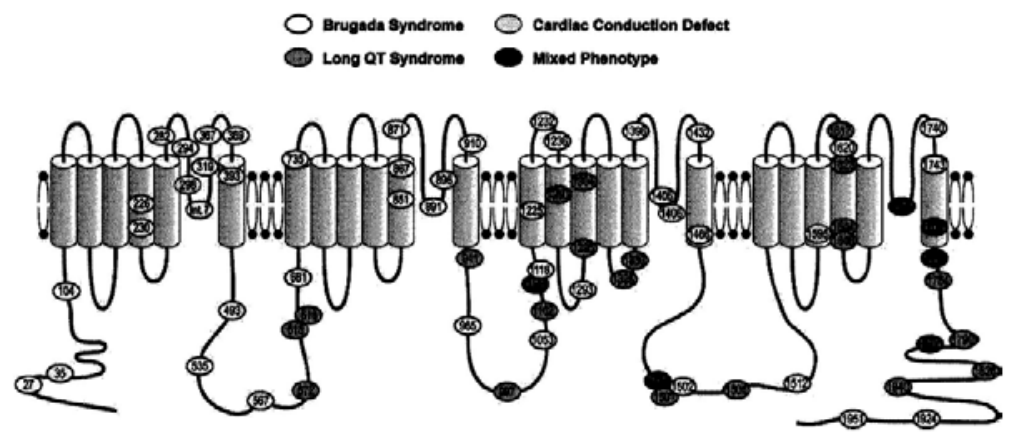

Fig. 12. Putative transmembrane organization of the sodium channel. The channel consists of 4 homologous domains, DI through DIV. The amino and carboxyl termini are intracellular. (Herbert \& Chahine, 2006).

Each sodium channel opens very briefly $(<1 \mathrm{~ms})$ during more than $99 \%$ of depolarizations (Patlak \& Ortiz, 1985). The channel occasionally shows alternative gating modes consisting of isolated brief openings occurring after variable and prolonged latencies and bursts of openings during which the channel opens repetitively for hundreds of milliseconds. The isolated brief openings are the result of the occasional return from the inactivated state. The bursts of openings are the result of occasional failure of inactivation (Patlak \& Ortiz, 1985). The cardiac sodium channel has consensus sites for phosphorylation by protein kinase, protein kinase C, and Ca-calmodulin kinase (Frohnwieser et al., 1997).

\subsection{1 $\mathrm{Na}^{+}$current changes}

Surviving border-zone tissue is characterized by reduced phase 0 amplitude and upstroke velocity $(\mathrm{dV} / \mathrm{dtmax})$, suggestive of reduced $\mathrm{I}_{\mathrm{Na}}$ (Spear et al., 1979). These abnormalities in 
excitability favor unidirectional block and reentry (Janse \& Wit, 1989). Isolated border-zone cardiomyocytes also have reduced $\mathrm{dV} / \mathrm{dtmax}$ (Lue \& Boyden, 1992) and marked abnormalities in $\mathrm{I}_{\mathrm{Na}}$, including reduced current density, accelerated inactivation, and slowed reactivation ( $\mathrm{Pu} \&$ Boyden, 1997). Computer simulations suggest that both $\mathrm{I}_{\mathrm{Na}}$ and $\mathrm{I}_{\mathrm{CaL}}$ abnormalities contribute to conduction abnormalities in the reentry circuit (Baba et al., 2005), in keeping with the key role of $\mathrm{I}_{\mathrm{CaL}}$ in the context of reduced coupling (Shaw \& Rudy, 1997). Protein kinase A activators partially improve $\mathrm{I}_{\mathrm{Na}}$ in peri-infarct zone cells, and the response to phosphatase inhibitors suggests that $\mathrm{I}_{\mathrm{Na}}$ is hyperphosphorylated (Baba et al., 2004). In late postinfarction rat cardiomyocytes, changes in $\mathrm{I}_{\mathrm{Na}}$ properties and in ion-channel subunit expression suggest the appearance of atypical $\mathrm{I}_{\mathrm{Na}}$ isoforms (Huang et al., 2001a); these changes may be due to generalized cardiac hypertrophy/dysfunction rather than infarction per se.

\subsubsection{Functional consequences}

Oxidative stress in postinfarction tissues produces reactive intermediates that alter INa in a fashion similar to arrhythmogenic $\mathrm{Na}_{\mathrm{v}} 1.5$ subunit mutations and potentiate the effects of $\mathrm{Na}^{+}$channel-blocking drugs (Fukuda et al., 2005). The INa blocker lidocaine differentially affects peri-infarct zone cardiomyocytes (Pu et al., 1998). These differential effects may contribute to the tendency of INa blockers to cause malignant ventricular tachyarrhythmias postinfarction (Ranger \& Nattel, 1995). These paradoxical "proarrhythmic" effects of INablocking antiarrhythmic drugs on myocardial infarction tissues contribute to a mortalityenhancing potential (Cardiac Arrhythmia Suppression Trial (CAST) Investigators, 1989).

\subsection{Therapeutic implications of ionic current and transporter remodeling}

\subsubsection{Remodeling-induced modification of the response to therapeutic interventions}

Myocardial infarction greatly increases the risk of arrhythmic death, and associated remodeling sensitizes patients to the proarrhythmic effects of a variety of drugs. The risk of drug-induced Torsades de Pointes arrhythmias caused by early afterdepolarizations is approximately increased by myocardial infarction (Stanley et al., 2007). Drugs like $\beta$ adrenergic agonists and phosphodiesterase inhibitors, which increase cardiac contractility by increasing intracellular cAMP concentrations, $\mathrm{Ca}^{2+}$ loading and $\mathrm{Ca}^{2+}$-induced $\mathrm{Ca}^{2+}$ release, have been used extensively to improve cardiac function in patients with severe cardiac dysfunction. Unfortunately, in the longer term they have arrhythmogenic actions and increase mortality (Gardner et al., 1985; Hagemeijer, 1993; Lubbe et al., 1992). Ionic remodeling likely contributes to these adverse responses.

Many of the changes responsible for adverse effects of antiarrhythmic drugs are caused by postinfarction myocardial remodeling: increased action potential duration, localized conduction slowing, downregulation of $\mathrm{K}^{+}$channels, abnormal diastolic $\mathrm{Ca}^{2+}$ handling, and impaired connexin function. Myocardial infarction predisposes to the proarrhythmic actions of $\mathrm{Na}^{+}$channel blocking drugs (Cardiac Arrhythmia Suppression Trial (CAST) Investigators, 1989; Ranger \& Nattel, 1995) and $I_{\mathrm{Kr}}$ blocking agents (Waldo et al., 1996). Responses to $\mathrm{I}_{\mathrm{Kr}}$ blocking drugs may be reduced in postinfarction cells, perhaps because of $\mathrm{I}_{\mathrm{Kr}}$ downregulation (Yuan et al., 1999).

\subsection{2 lonic remodeling as a target for novel therapeutic approaches}

Much less work has been done to study interventions targeting ion-handling processes postinfarction. An angiotensin-converting enzyme inhibitor attenuated increases in refractoriness heterogeneity and prevented afterdepolarization formation in normal zones of 
rats with prior infarctions (Li et al., 2004). The combined $\alpha$ - and $\beta$-adrenoceptor antagonist carvedilol suppresses downregulation of both $\mathrm{Na}^{+}$(Maltsev et al., 2002) and L-type $\mathrm{Ca}^{2+}(\mathrm{Li}$ et al., 2005) currents following myocardial infarction. Protein kinase A activators can partially restore suppressed $\mathrm{I}_{\mathrm{Na}}$ in the infarct border zone (Baba et al., 2004).

Advances in molecular cardiology have identified several potential targets for gene therapy. In a porcine model, focal gene transfer in the border zone of myocardial infarction to silence the $\mathrm{KCNH} 2$ potassium channel has been shown to abolish ventricular arrhythmias (Sasano et al., 2006). Furthermore, overexpression of the HERG potassium channel in isolated rabbit ventricular myocytes shortens action potential duration and reduces the frequency of early after-depolarizations (Nuss et al., 1999). Additional investigation is needed to confirm the safety and efficacy of targeted gene therapy in human. However, successful transition of gene therapy into clinical therapies will require the development of safe and efficient transgene vectors and delivery systems.

\section{Cardiac gap junction remodeling}

\subsection{Gap junction structure, permeability and regulation}

The gap junction, a type of cell-to-cell junction, is composed of low-resistance intercellular pathways and mediates electrical and metabolic coupling between adjacent cells. Each gap junction channel is formed by two end-to-end connected hemichannels (also known as connexons) contributed by each of the two adjacent cells. In chordates, hemichannels are hexameric structures formed by six connexins (Cx). Connexins have four transmembrane domains with two extracellular loops and with the N-terminal and C-terminal domains in the cytoplasm (Harris, 2001; Sosinsky, 2000). Twenty different connexin types have been identified in mouse and 21 in man (Sohl \& Willecke, 2004). Cells can usually express a variety of connexins, and the six connexins forming a hemichannel may not be identical (for example Cx43 and Cx40), thus forming a heteromeric hemichannel. Although not all combinations are possible (Harris, 2001), hemichannels formed by a particular connexins can dock to hemichannels with a different composition (Harris, 2001). A principal ultrastructural feature of the intercalated disk and gap junction was illustrated in Figure 13

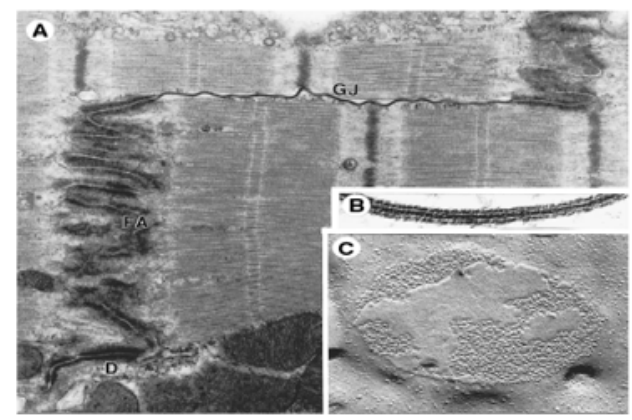

Fig. 13. Principal ultrastructural features of the intercalated disk and gap junction. A, Thinsection electron micrograph showing the appearance of the 3 types of cell-cell junction, the gap junction (GJ), fascia adherens (FA), and desmosome (D). B, Higher magnification thinsection of a gap junction. C, Structure of gap junction as revealed by freeze-fracture electron microscopy. The gap junction is seen as a cluster of particles. Each particle represents a connexon hemichannel. (a) $\times 36,250$; (b) $\times 350,000$; (c) $\times 98,000$ (Severs et al., 1993). 
(Severs et al., 1993). Gap junction are permeable to relatively large molecules (Harris, 2001). Depending on the connexins type, pore diameter ranges between approximately 6.5 and $15 \mathrm{~A}^{\circ}$ (Harris, 2001), which is wide enough to allow the passage of water, all relevant cations and anions, including $\mathrm{Na}^{+}, \mathrm{K}^{+}$, and $\mathrm{Ca}^{2+}$ and most second messengers as $\mathrm{IP}_{3}$, cAMP, and cGMP (Figure 14) (Harris, 2001; Wong et al., 2008).

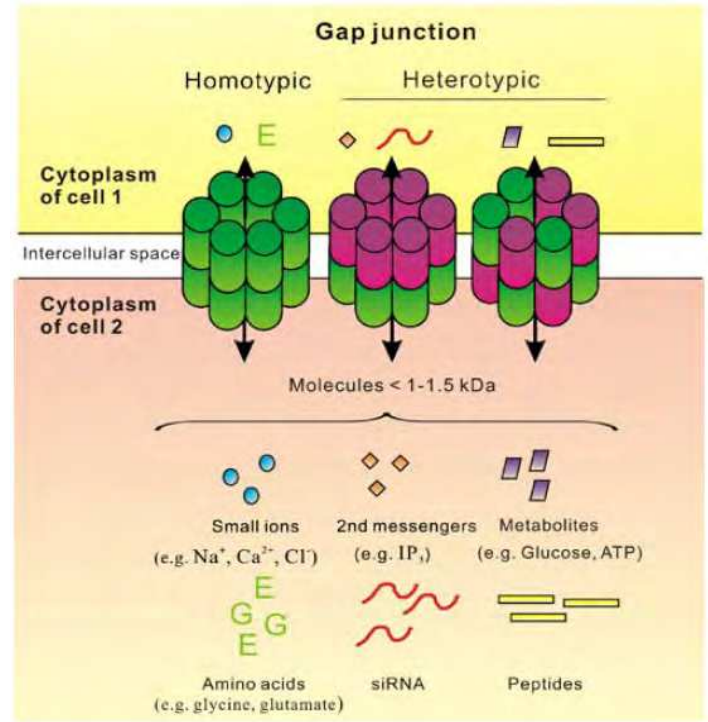

Fig. 14. Organisation of connexins into gap junctions and molecules capable of diffusing through gap junctions (Wong et al., 2008).

The mechanisms by which gap junction channel close or open are not fully elucidated. Gating can take place in at least two independent ways: a rapid, voltage-driven mechanism that can change the channel conformation between a fully open and a nearly completely closed state within a few ms (voltage gating), and a slower (up to $30 \mathrm{~ms}$ ) mechanism (Harris, 2001; Moreno et al., 2002a). Phosphorylation alters the probability of the different conductance states as well as intracellular trafficking and assembly of connexins depending on the connexins type, the phosphorylation site and, possibly, the biochemical environment (Van et al., 2001). The half-life of connexins is relatively short (less than 2h for Cx43) (Laing \& Beyer, 2000) so that changes in the rates of synthesis or degradation are rapidly translated into changes in the number of operative gap junction channel.

\subsection{Diversity of connexin expression in the normal heart}

Three principal connexins are expressed in cardiac myocytes, Cx43, Cx40, and Cx45. Although $\mathrm{C} \times 43$ predominates in the heart as a whole, it is typically co-expressed in characteristic combinations and relative quantities with Cx40 and/or Cx45 in a chamberrelated and myocyte-type-specific manner (Vozzi et al., 1999). Although a few other connexins have been reported in cardiac tissue, these are minor components, species variants, or not been confirmed. Figure 15 gives an overview of the typical connexin expression patterns of the normal adult mammalian heart (Severs et al., 2008). 


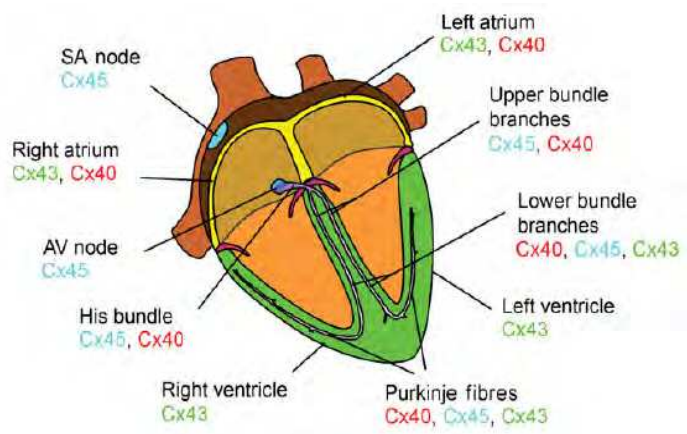

Fig. 15. Summary of the typical connexin expression patterns of the mammalian heart (Severs et al., 2008).

The working cardiomyocytes of the ventricle are extensively interconnected by clusters of connexin43-containing gap junctions located at the intercalated disks (Figure 16) (Severs et al., 2004). The intercalated disks of working ventricular myocardium have a step-like configuration, with the gap junctions situated predominantly in the membrane segments that lie parallel with the long axis of the cell (Severs, 1990), with larger gap junctions typically circumscribing the disk periphery (Gourdie et al., 1991). This and other features of gap junction organization and aspects of tissue architecture such as the size and shape of the cells combine to ensure preferential propagation of the impulse in the longitudinal axis and hence the normal pattern of anisotropic spread of the impulse of healthy ventricular myocardium.

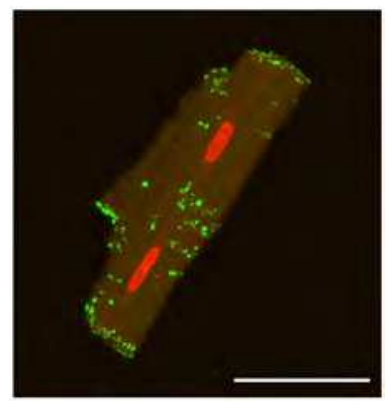

Fig. 16. An isolated ventricular myocyte labelled for Cx43 (green) illustrating localization of the gap junctions in clusters at the intercalated disks (Severs et al., 2004).

The gap junctions of atrial myocytes contain abundant Cx40 (Vozzi et al., 1999; Dupont et al., 2001), co-localized with Cx43 within the same individual gap-junctional plaques (Severs et al., 2001). Working ventricular myocytes, by contrast, normally lack detectable Cx40. In both ventricular and atrial working myocardium, Cx45 is present in very low quantities (Vozzi et al., 1999; Dupont et al., 2001). The specialized cardiomyocytes of the impulse generation and conduction system are distinct from the working ventricular and atrial cells both in terms of general morphology (Severs, 1989) and connexin expression profiles (Figure 17) (Coppen et al., 1999). 


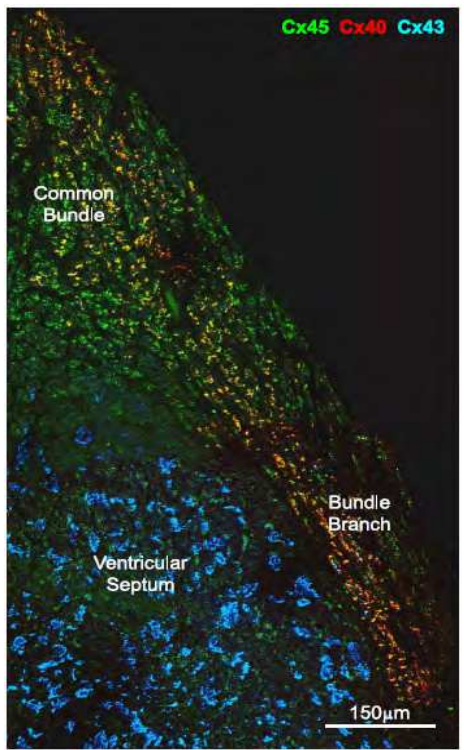

Fig. 17. Expression patterns of $C \times 43, C \times 40$ and $C \times 45$ in different cardiomyocyte sub-types. This triple-labelled confocal montage shows part of the conduction system (common bundle and right bundle branch) which expresses $\mathrm{C} \times 40$ and $\mathrm{Cx} 45$ ). These two connexins are not detected in the adjacent working ventricular myocytes of the septum, which instead express Cx43. This example comes from rat heart (Coppen et al., 1999).

\subsection{Gap junction remodeling in myocardial infarction 4.3.1 Connexin 43 remodeling in myocardial infarction}

Two principal gap junction-related alterations have been reported in the diseased ventricle: disturbances in the distribution of gap junctions and reduced levels of their major component, Cx43. "Lateralization" of Cx43 gap junction label is a prominent feature of the border zone of surviving myocytes around infarct scar tissue in the human ventricle (Smith et al., 1991). Electron microscopy reveals that both laterally disposed gap junctions connecting adjacent cells, and internalized (non-functional) gap junctional membrane, contribute to this abnormal pattern (Smith et al., 1991).

By 6-12h after ligation, the normal distribution was lost for Cx43, desmoplakin, and cadherin at the intercalated disks in the infarct zone. By $24-48 \mathrm{~h}$ after ligation, the expression of Cx43 markedly decreased, to $5 \%$ of the levels of shamoperated hearts (Figure 18) (Takamatsu, 2008). At 4 days post-infarction in a dog model, lateral gap junction label in the extended infarct border zone has been correlated spatially with electrophysiologically identified figure-of-eight re-entrant circuits (Peters et al., 1997).

Gap junctional changes distant from the infarct scar tissue, in particular reduction in the size and the number of gap junctions per unit length of intercalated disc, and fewer side-to-side connections between myocytes, have been described as longer term remodelling events in dog myocardium (Kostin et al., 2003). Our study showed that Cx43 mRNA and Cx43 protein reduced significantly at ischemic zone at 4,8 and 12 weeks of myocardial infarction mice (Figure 19) (LI et al., 2010; Zhao et al., 2009). 


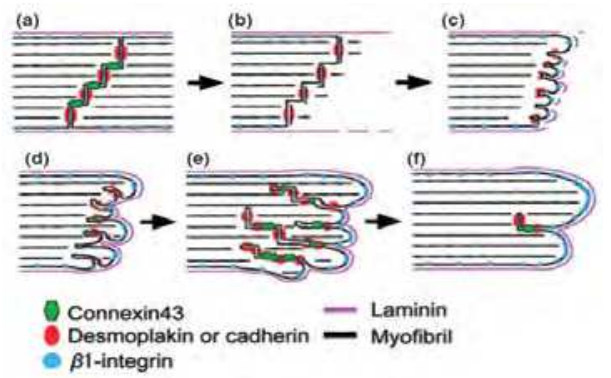

Fig. 18. Remodeling process of cell-cell and cell-extracellular matrix (cell-ECM) interactions at the stump of myocardial infarction. (a) Normal; (b) 24-48 h. At early phase after ligation (to $48 \mathrm{~h}$ ), borderline cardiomyocytes facing the infarct lose neighboring cells and form bluntended stumps while maintaining some desmoplakin, and cadherin loses Cx43. (c) 48 h-day 3. By day 3 , integrins such as b1-integrin cluster at stumps where basement membranes are partially formed. The formation of intracellular junctions composed of desmoplakin and cadherin is initiated between cell processes. (d) Days 3-4; (e) days 8-15, After day 3, stumps change into fine cytoplasmic processes toward the infarct. Cx43 expression between cell processes forms intracellular junctional complexes with desmoplakin and cadherin, similar to those of typical intercalated disks. Cx43 expression is also observed at transverse cell boundaries of borderline and vicinity cardiomyocytes. (f) In the chronic phase (days 60-90), integrin-ECM couplings at the tips of cell processes and collagen accumulation around the processes increase as wound healing proceeds. Cell processes fuse together, and the intercalated disk-like structures diminish (Takamatsu, 2008).

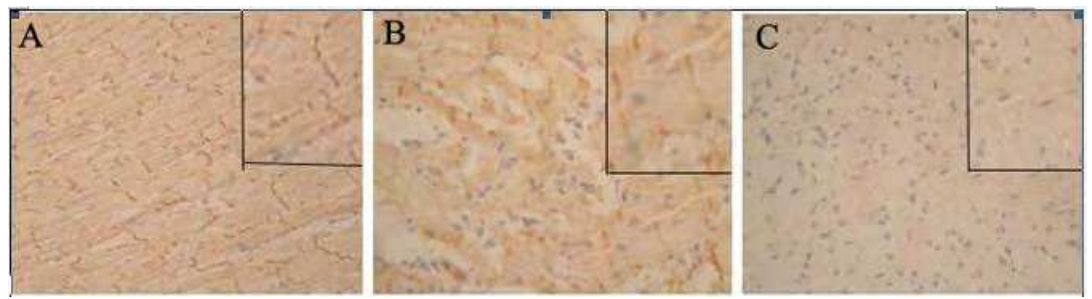

Fig. 19. A, Cx43 expression at normal zones in myocardial infarction mice after 4 weeks; B, Cx43 expression at ischemic zones in myocardial infarction mice after 4 weeks; C, Cx43 expression at infarcted zones in myocardial infarction mice after 4 weeks $(\times 400)($ LI et al., 2010).

Apart from alterations in connexin43 level, rapid dephosphorylation of Cx43 and translocation of $\mathrm{C} \times 43$ from gap junctions into the cytosol has been reported when electrical uncoupling is induced by acute ischaemia in the Langendorff-perfused rat heart (Beardslee et al., 2000). These processes are reversible upon reperfusion and substantially reduced with ischemic preconditioning (LI et al., 2009a). Dephosphorylated Cx43 is associated with the laterally distributed gap junction label, while those gap junctions that remain in the classic, polar intercalated disc orientation contain phosphorylated Cx43 (Lampe et al., 2006).

A rather different form of gap junction remodelling is associated with 'hibernating myocardium' in patients with ischemic heart disease (Kaprielian et al., 1998). The term 
'hibernating myocardium' refers to regions of ventricular myocardium that do not contract properly but which recover after normal blood flow is restored following coronary artery bypass surgery. In hibernating myocardium, the large Cx43 gap junctions typically found at the periphery of the intercalated disc are smaller in size, and the overall amount of immunodetectable Cx43 per intercalated disc is reduced, compared with normally perfused myocardial regions of the same heart (Kaprielian et al., 1998). These findings were the first indication that $\mathrm{Cx} 43$ gap junction remodelling contributes to impaired ventricular contraction, in addition to arrhythmia, in human ischemic heart disease (Kaprielian et al., 1998).

\subsubsection{Connexin 45 remodeling in myocardial infarction}

Because Cx45 is not expressed widely in working ventricular myocytes in the normal adult heart, there is no report on the alternation of distribution and expression of Cx45 after myocardial infarction. However, previous study showed that expression of $\mathrm{C} \times 45$ in the failing human ventricle was up-regulated, alongside the reduction in Cx43, thus significantly altering the Cx43: Cx45 ratio (Yamada et al., 2003). Our datas showed that Cx45 mRNA and Cx45 protein increased significantly at ischemic zone at 4,8 and 12 weeks in myocardial infarction mice (Figure 20) (Zhao et al., 2009). Up-regulation of Cx45 in myocardial infarction hearts inplicates a novel mechanism whereby connexin remodeling may promote arrhythmogenesis.

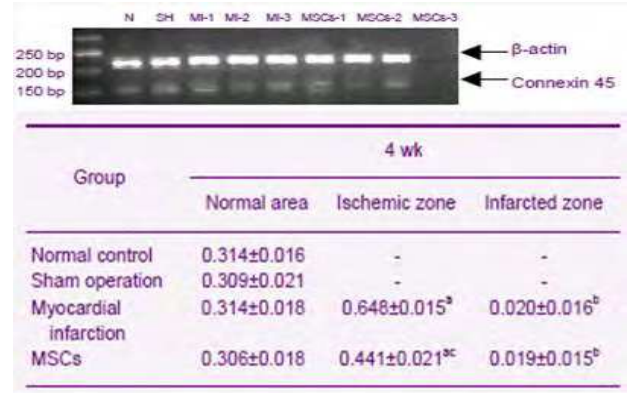

Fig. 20. Ratio change of connexin $45 / \beta$-actin for myocardial infarction mice after 4,8 and 12 weeks MSCs, bone marrow mesenchymal stem cells; aP < 0.01, vs. the normal area in the same group; $\mathrm{b} P<0.01$, vs. the ischemic zone in the same group; $\mathrm{cP}<0.01$, vs. myocardial infarction group (Zhao et al., 2009).

\subsubsection{Possibility of formation of heteromeric gap junction channels in myocardial infarction}

Expression of multiple connexin isoforms induces the formation of hetero-multimeric gap junction channels with distinct gating and permeability properties than their homomultimeric counterparts. Cx43 and Cx45 can form heterotypic channels that have unitary conductances lower than those of homotypic Cx43 channels and that fail to pass the fluorescent dye Lucifer yellow (Zhong et al., 2002; Moreno et al., 2002b; Moreno et al., 1995). When Cx43-expressing ROS cells are transfected to coexpress Cx45, electrical coupling is reduced even though $\mathrm{C} \times 43$ abundance, phosphorylation, and localization do not change (Koval et al., 1995). Coexpression of Cx45 with Cx43 in HeLa cells reduced the number of neighboring cells that were chemically coupled. Thus, increased Cx45 expression may 
reduce coupling and slow conduction or create microheterogeneities in coupling without slowing macroscopic conduction (Yamada et al., 2003).

Previos studies showed that heterotypic combination of Cx45 and Cx43 in mammalian cell lines impairs voltage gating of $\mathrm{C} \times 43$ and alters residual conductances, suggesting that connexon interactions may play a distinct role in modulation of intercellular communication (Elenes et al., 2001; Thomas et al., 2004). Cx43 and Cx45 formed heteromeric channels that exhibit reduced single channel conductance compared with $\mathrm{Cx} 43$ homomeric channels (Martinez et al., 2002). Our datas demonstrated colocalization of Cx45 and Cx43 in both control and ischemic ventricular myocardium (Figure 21).

Not only do Cx45 and Cx43 form hybrid channels in vitro, colocalization of these connexins in ventricular myocyte gap junctions provides and opportunity for hybrid channel formation in vivo, where interaction between Cx45 and Cx43 in hybrid channels could alter conductance states and gating responsiveness relative to the biophysical properties of homotypic channels (Yamada et al., 2003; Moreno et al., 2004). Our dates further suggested that enhanced expression of $\mathrm{C} \times 45$ in the ischemic heart occurs in junctions containing reduced levels of $\mathrm{Cx} 43$, raising the intriguing possibility that the relative stoichiometries of Cx45 and Cx43 within gap junctional plaques may be dramatically altered in the ischemic heart (Zhao et al., 2009). The limitation for our study is that the colocalization data are qualitative. In the absence of technological support of electrophysiologic confirmation of hybrid gap junction channels connecting ventricular myocytes in vivo, we can only speculate on the functional effects of increased $C \times 45$ in the myocardial infarction heart.

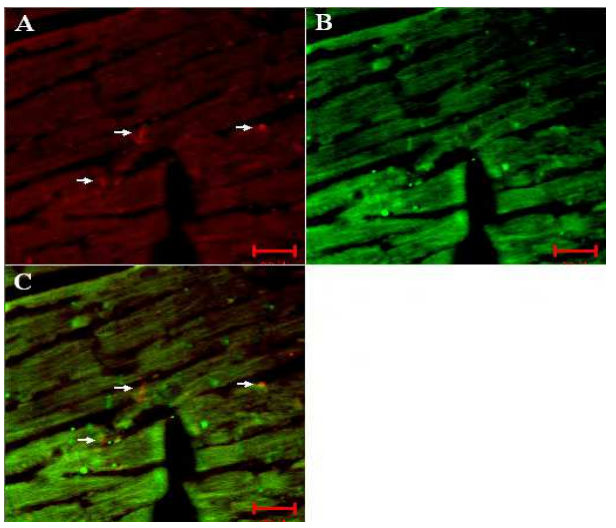

Fig. 21. Colocalizations (white arrows) of Cx45 and Cx43 in ischemic ventricular myocardium after 12 weeks in myocardial infarction mice by confocal microscopy examination (Scale bar $=20 \mu \mathrm{m})$.

\subsubsection{Mitochondrial Cx43 in myocardial infarction}

Although it is generally assumed that Cx43 is exclusively localized at the sarcolemma, Cx43 has been found recently at cardiomyocyte mitochondria linner and outer membrane (Boengler et al., 2005; Rodriguez-Sinovas et al., 2006; Goubaeva et al., 2007). Boengler et al (Boengler et al., 2005) presented evidence at first for the presence of $C \times 43$ in mitochondria from mouse, rat, pig and human left ventricular myocardium obtained from fluorescence-activated cell sorting and western blot analyses, as well as confocal and immunoelectron microscopy (Figure 22). 


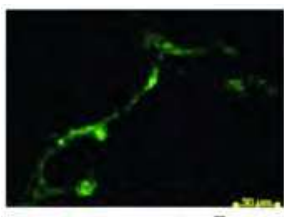

Ox-Phos complex II

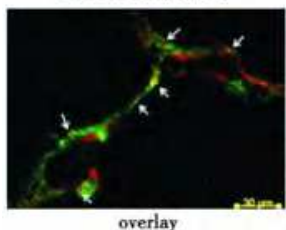

overlay

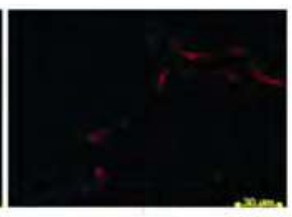

$\mathrm{Cx} 43$

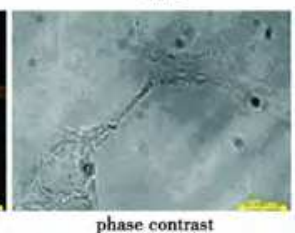

Fig. 22. Cultured mice atrial HL-1 cardiomyocytes were stained with antibodies against Cx43 (red) and mitochondria (Ox-Phos Com plex II, green) and analyzed by confocal laser scan microscopy. Merged image demonstrates colocalization as yellow po ints (arrows). Additional ly, the phase contrast image was shown (Boengler et al., 2005).

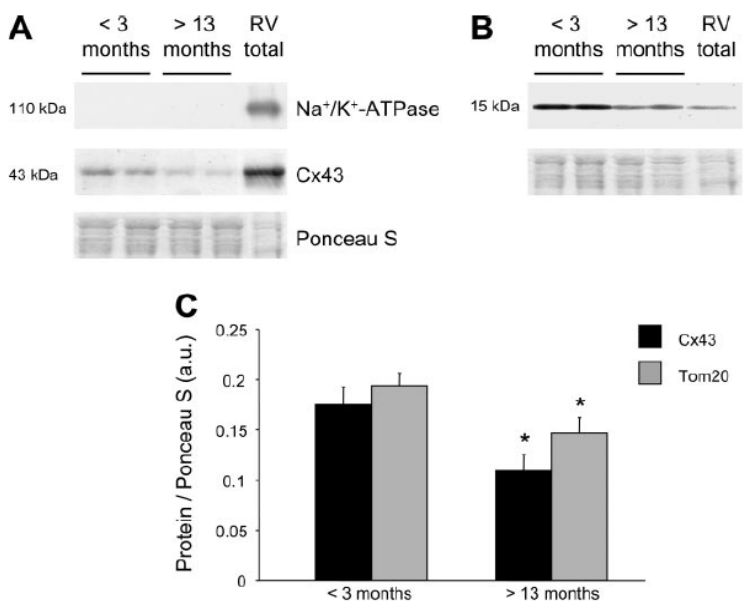

Fig. 23. Cx43 and translocase of the outer membrane 20 (Tom20) protein level in mitochondria isolated from left ventricular mycardium from young and aged mice. A: Western blot analysis was performed on mitochondrial protein extracts from young $(<3 \mathrm{mo})$ and aged $(>13 \mathrm{mo})$ mice and on total right ventricular proteins $(<3 \mathrm{mo})$ for Na-K-ATPase and Cx43. Ponceau S staining demonstrates equal protein loading. B: Western blot analysis was performed for Tom 20 on mitochondrial protein extracts from young and aged mice and on total right ventricular proteins. Ponceau S staining demonstrates equal protein loading. C: quantification of the Cx43 and Tom 20 immunoreactivity in mitochondria of young ( $<3 \mathrm{mo}, \mathrm{n}=14)$ and aged ( $>13 \mathrm{mo}, \mathrm{n}=10$ ) mice normalized to Ponceau $S$ staining. ${ }^{*} \mathrm{P}<0.05$ vs. $<3$ mo (Boengler et al., 2007).

In Antonio et al (Rodriguez-Sinovas et al., 2006) study, treatment of isolated mitochondria with digitonin resulted in a marked reduction of voltage dependent anion channel immunoreactivity (VDA), whereas an adenine nucleotide transporter (ANT) specific signal was detected by confocal laser scan microscopy. An observations, by using western blotting 
and immunofluorescence with anti-VDAC as a marker for the outer mitochondrial membrane and with anti-ANT as a marker for the inner mitochondrial membrane, confirmed that $\mathrm{C} \times 43$ was not only present in the inner and outer mitochondrial membrane, but the mitochondrial Cx43 is phosphorylated (Goubaeva et al., 2007). Furthermore, with progressing age, GJ and mitochondrial levels of $\mathrm{C} \times 43$ in ventricular and atrial tissue homogenates are reduced. In mice hearts, sarcolemmal Cx43 content was reduced in aged (> 13 month) com pared with young ( $<3$ month). Also in mitochondria isolated from aged mice left ventricular myocardium, western blot analysis indicated a $40 \%$ decrease in Cx43 content compared with mitochondria isolated from young mice hearts. The reduced levels of Cx43 may contribute to the age-related loss of cardioprotection (Figure 23) (Boengler et al., 2007).

There is very little research on the relationship between mitochondria connexin and myocardial infarction until now, and Cx43 is the only connexin that has been found at cardiomyocyte mitochondria. Recentlly, our data showed that Heptanol (a GJ blocker) preconditioning protects myocardium from ischemia-reperfusion injury. The mechanism may be related to increasing in mitochondrial membrane potential and attenuating the decrease in mitochondria Cx43 expression induced by isehemia-reperfusion (Figure 24) (HE, $2009,2010)$.

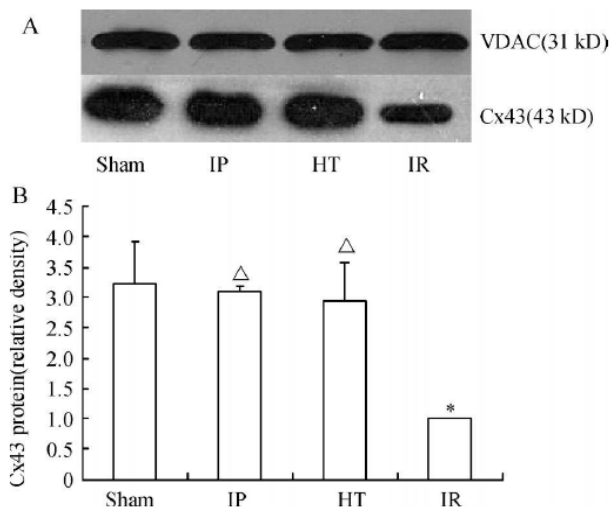

Fig. 24. Western blotting ( $30 \mu \mathrm{g}$ total protein / lane) shows the increase of Cx43 protein in myoca rdial mitochondria in heptanol preconditioning on myocardial isehemia/reperfusion injury of rabbits. A: expression of $\mathrm{C} x 43$ protein detected by Western blotting; B: results of the relative density of $C \times 43$ protein; $n=3 .{ }^{\triangle} \mathrm{P}<0.05$ vs IR; ${ }^{*} \mathrm{P}<0.05$ vs sham $(\mathrm{HE}, 2009,2010)$.

\subsection{Electrophysiological consequences of gap junction remodeling}

Reductions in intercellular coupling lead to slowing of impulse propagation and amplification of the normal electrical heterogeneity within the ventricular myocardium. Individually, each of these electrophysiological effects of uncoupling are predicted to favor reentry, and together they may very well synergistically enhance arrhythmic risk (Kleber \& Rudy, 2004).

Anatomic evidence of GJ remodeling, typically documented by immunohistochemical means, has been correlated with functional measures of aberrant cell-cell coupling such as slowing of impulse propagation and changes in anisotropy, as well as arrhythmogenicity 
(Fishman, 2005). In the healing canine infarct model, areas of GJ remodeling characterized by redistribution of $\mathrm{Cx} 43$ to lateral cell borders, correlates with the location of the central common pathway of figure-of-eight reentrant circuits (Peters et al., 1997). Additionally, junctional conductance of side-to-side coupled cells from the epicardial border zone is markedly diminished (Yao et al., 2003).

What needs to be noted is that dysregulated connexin expression occurs as but one element of a widespread remodeling process - one that in volves many of the ion-handling proteins that regulate cardiac excitability (Fishman, 2005). Cardiac-specific Cx43 gene-targeted mutant mice showed significant slowing of impulse propagation and despite the relatively small mass of the murine ventricle, they all succumb to spontaneous or easily inducible sustained ventricular tachyarrhythmias (Fishman, 2005). Moreover, optical mapping studies suggest that most, if not all of these arrhythmias are due to reentry (Gutstein et al., 2001).

On the other hand, studies of several additional genetic models in which Cx43 expression is modified are instructive, including the heteryzygous $\left(\mathrm{C} \times 43^{+/-}\right)$germline knockout mice,


(Guerrero et al., 1997). Taken together, data from these murine models suggest that in the absence of additional pathologic stimuli, less widespread or more modest reductions in cellcell coupling are insufficient to support sustained ventricular arrhythmias (Fishman, 2005).

For example, Cx43 germline heterozygous mice subjected to myocardial infarction reportedly have no increase in the frequency of spontaneous or inducible arrhythmias compared to wildtype mice with infarcts (Betsuyaku, 2004). Moreover, the imposition of ischemia in isolated-perfused hearts from $\mathrm{C} \times 43^{+/-}$mice provokes only non-sustained ventricular tachycardia (Lerner et al., 2000). Cx43 chimeric mice, which have relatively large foci of uncoupled myocytes within the ventricle, display a substantial increase in spontaneous PVCs and short runs of VT (Gutstein et al., 2005). The O-CKO mice only develop inducible or spontaneous sustained VT when the anatomic extent of knockout is marked, encompassing more than $60 \%$ of the myocardium (Danik et al., 2004). Thus, the spatial extent and magnitude of uncoupling of Cx43 is likely to be insufficient to support the development of sustained ventricular tachyarrhythmias in the absence of additional pathologic pro-arrhythmic" hits" (Fishman, 2005).

\subsection{Therapeutic Implications of gap junction remodeling after myocardial infarction 4.5.1 Pharmacological therapeutic implications}

Pharmacology of GJ intercellular communication is still at its beginnings. Figure 26 shows a schematic view of a gap junction channel as a target of pharmacology (Salameh \& Dhein, 2005). Potential mechanisms controlling the level of intercellular communication in the heart include regulation of connexin turnover (synthesis and degradation), cellular distribution and phosphorylation. There are numerous data showing that some compounds can upregulate $\mathrm{C} \times 43$ via modulation either synthesis or degradation and enhance gap junctional communication (Salameh \& Dhein, 2005). Although many substances have effects on Gap junction-mediated intercellular communication (GJMIC), there is a lack of powerful and specific GJ blockers (Dhein, 1998, 2005).

Substances, such as AAP10 (Weng et al., 2002) or its derivative ZP123 (Xing et al., 2003), that increase intercellular coupling have presented themselves as valuable new tools to investigate the role of intercellular coupling in physiology and pathophysiology. It has been shown that uncoupling correlates with the development of some types of arrhythmias, and in several cases application of drugs that increase coupling has confirmed this role (Axelsen 


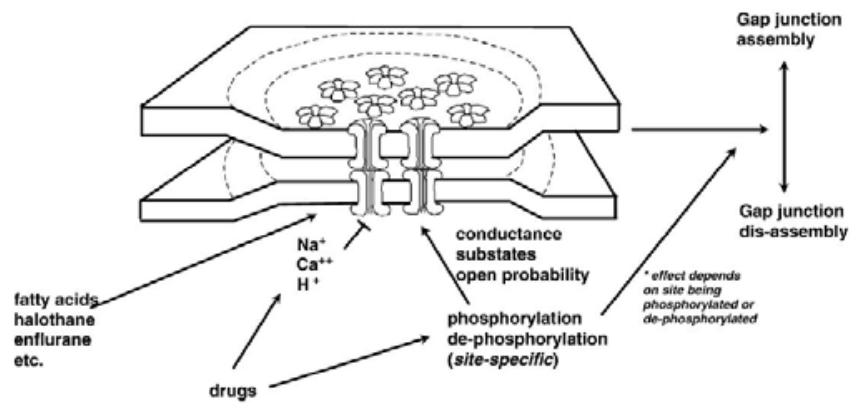

Fig. 26. Schematic view of a gap junction channel and its constituent component, the connexin, as a target of pharmacology (Salameh \& Dhein, 2005).

et al., 2007). Two recent studies showed (Haugan et al. 2005, Axelsen et al. 2007 (Haugan et al., 2005; Axelsen et al., 2007) that an increase of gap junctional conductance by specific peptide, rotigaptide, can prevent atrial conduction slowing or re-entrant ventricular tachycardia in ischemic heart. Suppression of ischemia-induced dephosphorylation of connexin seems to be one of the mechanisms involved. This mechanism was thought to be involved in the antiarrhythmic effects of ischemic preconditioning (Schulz et al., 2007). On the other hand, the reduction in gap junction communication that takes place during ischemia has been regarded as a beneficial and protective measure (Garcia-Dorado et al., 2004). Several investigators have examined the role of uncoupling GJ communication on myocardial infarct size. Thus, pharmacological uncoupling of GJ communication with nonselective uncouplers of GJ communication has been reported to reduce infarct size in animal experiments. Addition of the GJ blocker heptanol at concentration has a marked protective effect when applied at the time of reperfusion (Garcia-Dorado et al., 1997). Recent studies analyzing the effect of GJ uncouplers when administered during reoxygenation or reperfusion have consistently documented a reduction of necrosis (enzyme release or infarct size) (Saltman et al., 2002; Sebbag et al., 2003). Besides, electrical uncoupling by heptanol significantly lowers defibrillation threshold and dispersion of ventricular fibrillation cycle length without altering refractoriness (Qi et al., 2003). Although the beneficial and protective effort of GJ uncouplers delighted our researches, an important limitation is the lack of specific, rapid, reversible, and safe inhibitors of GJ intercellular communication.

Modulation of GJ intercellular coupling may open interesting new therapeutic approaches for a large number of diseases including myocardial infarction. However, in many respects, we have not completely understood the complex networking and its long-term regulation. This again underlines the need for in vivo and organbased models to evaluate the possibilities of pharmacological approaches towards an acute or chronic modulation of gap junctions. Moreover, the development of connexin- or organ specific gap junction modulator drugs is a challenging task for pharmacologists.

\subsubsection{Stem cell therapy}

Stem cell transplantation has emerged as a potential treatment strategy for heart failure secondary to acute or chronic ischaemic heart disease (Laflamme \& Murry, 2005). But currently two autologous cell types, namely bone marrow (BM) cells and skeletal myoblasts (SMs), which were used in clinical trials in patients after myocardial infarction (Murry et al., 
2005), seem to provide only modest improvement of contractile heart function (Janssens et al., 2006) because neither BM cells (Murry et al., 2004) nor SMs (Reinecke et al., 2002) adopt a cardiac cell fate or couple electrically with the host myocardium (Leobon et al., 2003; Murry et al., 2004). Moreover, VT has been reported in several of the patients transplanted with SMs (Hagege et al., 2006), raising concerns as to whether engraftment of cells enhances the risk of VT, the most frequent cause of sudden death after myocardial infarction (Solomon et al., 2005; Henkel et al., 2006). So it is very important to fully answer these two questions before cell or stem cell therapy was proposed widely in clinic: whether cell or stem cell can differenciate into cardiomyocytes? Whether cell or stem cell can form functional coupling with the host, which is important for the physiological communication between cardiac myocytes?

A study (Virginijus et al., 2004) showed that human mesenchymal stem cells (hMSCs) can express connexins and couple to one another via $\mathrm{C} \times 43$ and $\mathrm{C} \times 40$. In addition, they formed functional gap junction channels with cells tranfected with Cx43, Cx40 or Cx45 as well as canine ventricular cardiomyocytes. Those are the foundermantal conditions for mesenchymal stem cells therapy for heart disease including myocardial infarction (see Figure 27).

Besides, another study (Wilhelm et al., 2007) showed that cardiomyocyte transplantation has the potential to impart electrical stability to the injured heart, thereby markedly reducing the major factor leading to sudden death. This protective effect was independent of the documented modest augmentation of left ventricular function and was associated with improved electrical coupling within the infarct by the engraftment of Cx43-expressing embryonic cardiomyocytes (eCMs). This enhanced coupling reduced vulnerability to VT by decreasing the incidence of conduction block within the infarct and/or by a modulatory effect on border-zone cardiomyocytes. This study also found that expression of the cardiac gap-junction protein $\mathrm{C} \times 43$ is the critical factor underlying augmented intercellular electrical conduction and protection from arrhythmia, because engraftment of Cx43-expressing SMs
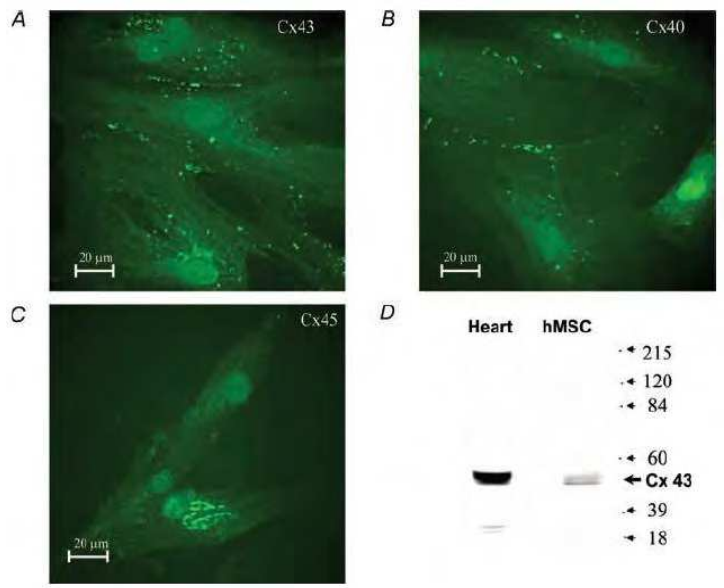

Fig. 27. Identification of connexins in gap junctions of hMSCs Immunostaining of Cx43 (A), Cx40 (B) and Cx45 (C). D, immunoblot analysis of Cx43 in canine ventricular myocytes and hMSCs. Whole cell lysates $(120 \mu \mathrm{g})$ from ventricular cells or hMSCs were resolved by SDS, transferred to membrans, and blotted with Cx43 antibodies. Migration of molecular weight markers is indicated to the right of the blot (Virginijus et al., 2004). 

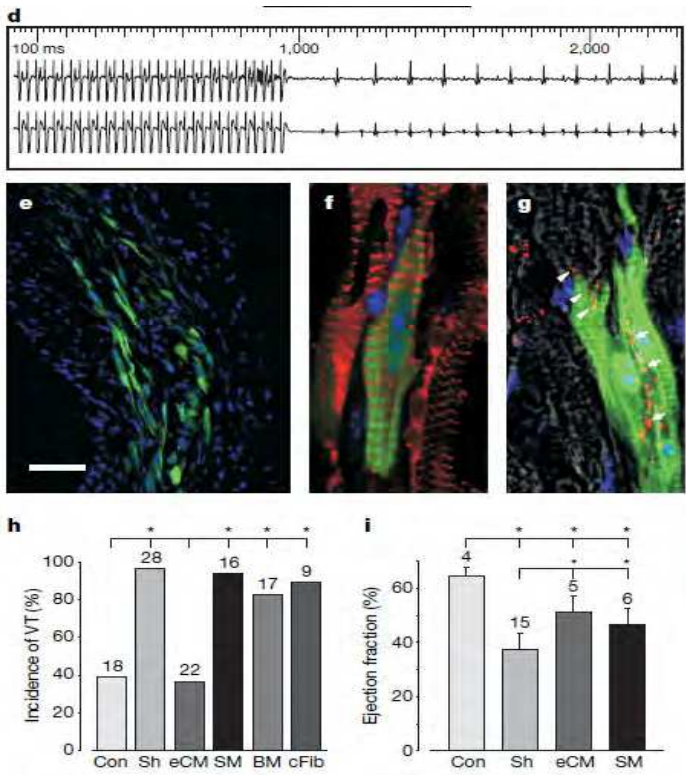

Fig. 28. d, Ventricular burst stimulation does not induce VT. Upper trace, surface ECG; lower trace, His-level electrogram. e, EGFP-positive eCMs integrate into the infarct. f, EGFP positive eCMs are striated (a-actinin staining, red) and are in direct contact with EGFPnegative host cardiomyocytes. g, Cx43 staining (red) illustrates gap-junction formation between engrafted EGFP-positive eCMs (arrows) and with native cardiomyocytes (arrowheads). h, Summary of VT inducibility. Note strongly elevated susceptibility to VT induction in shaminjected group (Sh) compared with control group; eCM engraftment reduces VT inducibility compared with sham injection. Conversely, VT remains frequent after transplantation of SMs, BM and cardiac myofibroblasts (cFib). i, Improvement of left ventricular ejection fraction after eCM or SM transplantation. Numbers above bars indicate $\mathrm{n}$; error bars show s.d. Scale bar, $60 \mathrm{~mm}(\mathrm{e}), 5 \mathrm{~mm}(\mathrm{f})$, and $11 \mathrm{~mm}(\mathrm{~g})$.

protected against VT induction (see Figure 28). Thus, cell therapy including stem cell therapy in combination with $\mathrm{C} \times 43$ gene transfer represents a promising therapeutic strategy to decrease the risk of potentially fatal arrhythmias in injured heart.

In our recently study on mice, Laser Scanning Confocal Microscope examination found that DAPI-labeled MSCs distributed widely at the host ischemic zone and expressed Cx43. Fluorescence PCR, Immunohistochemistry, Immunofluorescence and immuno-electron microscope studies showed that Cx43 mRNA and Cx43 protein exprssions were statistically higher in MSCs group compared to MI group; Cx45 mRNA and Cx45 protein expressions were statistically lower in MSCs group compared to MI group (see Figure 29). We concluded that MSCs transplantation, which could survive at the host ischemic zone and express Cx43, can modulate the electrophysiological abnormality of myocardial infarction by up-regulating Cx43 and down-regulating Cx45 both at Protein and mRNA levels. In a word, MSCs have the plasticity of differentiating into cardiac muscle cell-like cells, which can modulate the electrophysiological abnormality via regulation of $\mathrm{C} \times 43$ and $\mathrm{C} \times 45$ remodeling following with myocardial infarction (Li et al., 2009b, 2010; Zhao et al., 2009, 2010). 

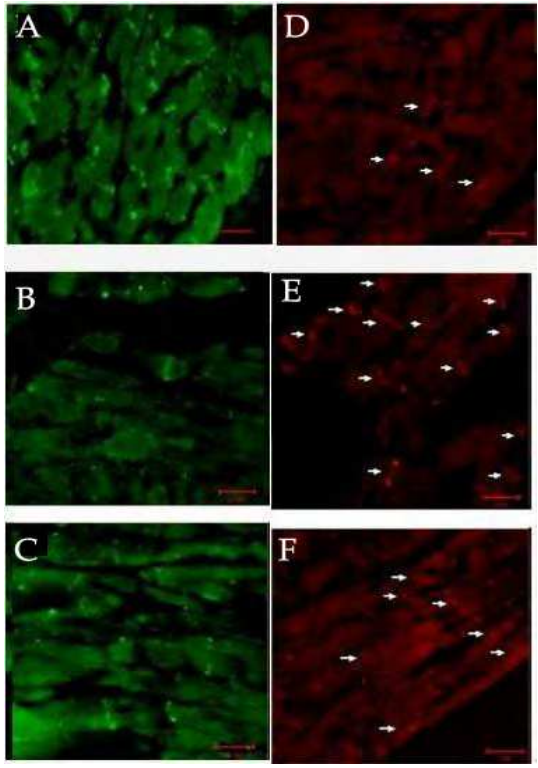

Fig. 29. A, Cx43 staining by FITC (green) at normal zones of ventricular myocardium. B, Cx43 staining by FITC at ischemic zones of ventricular myocardium. C, Cx43 staining by FITC at ischemic zones of ventricular myocardium after MSCs transplantation. D, Cx45 staining by TR (red) at normal zones of ventricular myocardium. E, Cx45 staining by TR at ischemic zones of ventricular myocardium. F, Cx45 staining by TR at ischemic zones of ventricular myocardium after MSCs transplantation.

\section{Conclusions and perspective}

In this chapter, we have presented mechanisms of sympathetic neural remodeling, electrical remodeling and gap Junction remodeling, which closely relate to the electrophysiological abnormality after myocardial infarction. Pathophysiological remodeling in myocardial infarction is multifactorial and complex, which involves changes in the structure and function of the myocardium. Although we anthropogenically divided the arrhythogenic mechamism of myocardial infarction into three parts, we have emphasized the importance of interrelationship among them which occurs at the cellular and molecular levels. Elucidating the role of myocardial remodeling and its molecular underpinnings present opportunities for the development of novel gene- and cell-based strategies as well as more pharmacotherapies. Besides, the localization of $\mathrm{C} \times 43$ at mitochondria opens a new door for us to reveal the cardioprotection against myocardial infarction. Stem cells, especially MSCs, give us a new hope on the potential treatment strategy for reducing life-threatening post-infarct arrhythmias and for heart failure secondary to acute or chronic ischaemic heart disease.

\section{Acknowledgment}

This work was supported by grants from the National Natural Science Foundation of China (No. 30560051); the Science Foundation for Returnees of Guangxi Zhuang Autonomous 
Region of China (No.0448014) and the Key Scientific Research Subject of Medical Treatment and Public Health of Guangxi Zhuang Autonomous Region of China (No.200301).

\section{References}

Aggarwal R \& Boyden PA. (1995). Diminished $\mathrm{Ca}^{2+}$ and $\mathrm{Ba}^{2+}$ currents in myocytes surviving in the epicardial border zone of the 5-day infarcted canine heart. Circ Res, Vol.77, No.6, pp. 1180-1191. ISSN 0009-7330

Armour, JA. (2010). Functional anatomy of intrathoracic neurons innervating the atria and ventricles. Heart Rhythm, Vol.7, No.7, pp. 994-996. ISSN 1547-5271

Augustus O. Grant. (2009). Cardiac Ion Channels. Circ Arrhythm Electrophysiol. 2, 185-194. ISSN 1941-3149

Axelsen LN, Haugan K, Stahlhut M, Kjølbye AL, Hennan JK, Holstein-Rathlou NH, Petersen JS \& Nielsen MS. (2007). Increasing Gap Junctional Coupling: A Tool for Dissecting the Role of Gap Junctions. J Membrane Biol, Vol.216, No.1, pp. 23-35. ISSN 0022-2631

Baba S, Dun W \& Boyden PA. (2004). Can PKA activators rescue $\mathrm{Na}^{+}$channel function in epicardial border zone cells that survive in the infarcted canine heart? Cardiovasc Res, Vol.64, No.2, pp. 260-267. ISSN 0008-6363

Baba S, Dun W, Cabo C \& Boyden PA. (2005). Remodeling in cells from different regions of the reentrant circuit during ventricular tachycardia. Circulation, Vol.112, No.16, pp. 2386-2396. ISSN 0009-7322

Beardslee MA, Lerner DL, Tadros PN, Laing JG, Beyer EC, Yamada KA, Kléber AG, Schuessler RB \& Saffitz JE. (2000). Dephosphorylation and intracellular redistribution of ventricular connexin43 during electrical uncoupling induced by ischemia. Circ Res, Vol.87, No.8, pp. 656-62. ISSN 0009-7330

Betsuyaku T, Kanno S, Lerner DL, Schuessler RB, Saffitz JE \& Yamada KA. (2004). Spontaneous and inducible ventricular arrhythmias after myocardial infarction in mice. Cardiovasc Pathol, Vol.13, No.3, pp. 156-164. ISSN 1054-8807

Boengler K, Dodoni G, Rodriguez-Sinovas A, Cabestrero A, Ruiz-Meana M, Gres P, Konietzka I, Lopez-Iglesias C, Garcia-Dorado D, Di Lisa F, Heusch G \& Schulz R. (2005). Connexin 43 in cardiomyocyte mitochondria and its increase by ischemic preconditioning. Cardiovasc Res, Vol.67, No.2, pp. 234-244. ISSN 0008-6363

Boengler K, Konietzka I, Buechert A, Heinen Y, Garcia-Dorado D, Heusch G \& Schulz R. (2007). Loss of ischemic preconditionings cardioprotection in aged mouse hearts is associated with reduced gap junctional and mitochondrial levels of connexin 43. Am J Physiol Heart Circ Physiol, Vol.292, No.4, pp. H1764-H1769. ISSN 0363-6135

Boyden PA, Albala A \& Dresdner KP Jr. (1989). Electrophysiology and ultrastructure of canine subendocardial Purkinje cells isolated from control and 24-hour infarcted hearts. Circ Res, Vol.65, No.4, pp. 955-970. ISSN 0009-7330

Boyden PA \& Pinto JM. (1994). Reduced calcium currents in subendocardial Purkinje myocytes that survive in the 24- and 48-hour infarcted heart. Circulation, Vol.89, No.6, pp. 2747-2759. ISSN 0009-7322

Boyden PA, Barbhaiya C, Lee T \& ter Keurs HE. (2003). Nonuniform $\mathrm{Ca}^{2+}$ transients in arrhythmogenic Purkinje cells that survive in the infarcted canine heart. Cardiovasc Res, Vol.57, No.3, pp. 681-693. ISSN 0008-6363 
Boyden PA, Dun W, Barbhaiya C \& ter Keurs HE. (2004). 2APB- and JTV519(K201)-sensitive micro $\mathrm{Ca}^{2+}$ waves in arrhythmogenic Purkinje cells that survive in infarcted canine heart. Heart Rhythm, Vol.1, No.2, pp. 218-226. ISSN 1547-5271

Canty JM Jr, Suzuki G, Banas MD, Verheyen F, Borgers M \& Fallavollita JA. (2004). Hibernating myocardium: chronically adapted to ischemia but vulnerable to sudden death. Circ Res, Vol.94, No.8, pp. 1142-1149. ISSN 0009-7330

Cao JM, Chen LS, KenKnight BH, Ohara T, Lee MH, Tsai J, Lai WW, Karagueuzian HS, Wolf PL, Fishbein MC \& Chen PS. (2000a). Nerve sprouting and sudden cardiac death. Circ Res, Vol.86, No.7, pp. 816-821. ISSN 0009-7330

Cao JM, Fishbein MC, Han JB, Lai WW, Lai AC, Wu TJ, Czer L, Wolf PL, Denton TA, Shintaku IP, Chen PS \& Chen LS. (2000b). Relationship between regional cardiac hyperinnervation and ventricular arrhythmia. Circulation, Vol.101, No.16, pp. 19601969. ISSN 0009-7322

Cardiac Arrhythmia Suppression Trial (CAST) Investigators. (1989). Preliminary report: effect of encainide and flecainide on mortality in a randomized trial of arrhythmia suppression after myocardial infarction. N Engl J Med, Vol.321, No.6, pp. 406-412. ISSN 0028-4793

Chow LT, Chow WH, Lee JC, Chow SS, Anderson RH \& Gosling JA. (1998). Postmortem changes in the immunohistochemical demonstration of nerves in human ventricular myocardium. J Anat, Vol.192, No.1, pp. 73-80. ISSN 0021-8782

Cittadini A, Monti MG, Isgaard J, Casaburi C, Strömer H, Di Gianni A, Serpico R, Saldamarco L, Vanasia M \& Saccà L. (2003). Aldosterone receptor blockade improves left ventricular remodeling and increases ventricular fibrillation threshold in experimental heart failure. Cardiovasc Res, Vol.58, No.3, pp. 555-564. ISSN 0008-6363

Coppen SR, Severs NJ \& Gourdie RG. (1999). Connexin45 (a6) expression delineates an extended conduction system in the embryonic and mature rodent heart. Dev Genet, Vol.24, No.1-2, pp. 82-90. ISSN 0192-253X

Crowley C, Spencer SD, Nishimura MC, Chen KS, Pitts-Meek S, Armanini MP, Ling LH, McMahon SB, Shelton DL \& Levinson AD. (1994). Mice lacking nerve growth factor display perinatal loss of sensory and sympathetic neurons yet develop basal forebrain cholinergic neurons. Cell, Vol.76, No.6, pp. 1001-1011. ISSN 0092-8674

Danik SB, Liu F, Zhang J, Suk HJ, Morley GE, Fishman GI \& Gutstein DE. (2004). Modulation of cardiac gap junction expression and arrhythmic susceptibility. Circ Res, Vol.95, No.10, pp. 1035-1041. ISSN 0009-7330

Desplantez T, Halliday D, Dupont E \& Weingart R. (2004). Cardiac connexins Cx43 and Cx45: formation of diverse gap junction channels with diverse electrical properties. Pfluqers Arch, Vol.448, No.4, pp. 363-375. ISSN 0031-6768

Dhein S. (1998). Gap junction channels in the cardiovascular system: pharmacological and physiological modulation. Trends Pharmacol Sci, Vol.19, No.6, pp. 229-41. ISSN 01656147

Dhein S, Polontchouk L, Salameh A \& Haefliger J.-A. (2002). Pharmacological modulation and differential regulation of the cardiac gap junction proteins connexin 43 and connexin 40. Biol Cell, Vol.94, No.7-8, pp. 409-22. ISSN 0248-4900 
Dillon SM, Allessie MA, Ursell PC \& Wit AL. (1988). Influences of anisotropic tissue structure on reentrant circuits in the epicardial border zone of subacute canine infarcts. Circ Res, Vol.63, No.1, pp. 182-206. ISSN 0009-7330

Dun W, Baba S, Yagi T \& Boyden PA. (2004). Dynamic remodeling of $\mathrm{K}^{+}$and $\mathrm{Ca}^{2+}$ currents in cells that survived in the epicardial border zone of canine healed infarcted heart. Am J Physiol Heart Circ Physiol, Vol.287, No.3, pp. H1046-H1054. ISSN 0363-6135

Dun W \& Boyden PA. (2005). Diverse phenotypes of outward currents in cells that have survived in the 5-day-infarcted heart. Am J Physiol Heart Circ Physiol, Vol.289, No.2, pp. H667-H673. ISSN 0363-6135

Dupont E, Ko Y, Rothery S, Coppen SR, Baghai M, Haw M \& Severs NJ (2001). The gapjunctional protein, connexin40, is elevated in patients susceptible to post-operative atrial fibrillation. Circulation, Vol.103, No.6, pp. 842-9. ISSN 0009-7322

Elenes S, Martinez AD, Delmar M, Beyer EC \& Moreno AP (2001). Heterotypic docking of Cx43 and Cx45 connexons blocks fast voltage gating of Cx43. Biophys J, Vol.81, No.3, pp. 1406-1418. ISSN 0006-3495

Esler M, Jennings G, Lambert G, Meredith I, Horne M \& Eisenhofer G (1990). Overflow of catecholamine neurotransmitters to the circulation: source, fate, and functions. Physiol Rev, Vol.70, No.4, pp. 963-985. ISSN 0031-9333

Fishman GI. (2005). Gap junction remodeling and ventricular arrhythmias. Heart Rhythm, Vol.2, No.8, pp. 887-9. ISSN 1547-5271

Friedman PL, Fenoglio JJ \& Wit AL. (1975). Time course for reversal of electrophysiological and ultrastructural abnormalities in subendocardial Purkinje fibers surviving extensive myocardial infarction in dogs. Circ Res, Vol.36, No.1, pp. 127-144. ISSN 0009-7330

Frohnwieser B, Chen, L-Q, Schreibmayer W \& Kallen RG. (1997). Modulation of the human cardiac sodium channel a-subunit by cAMP-dependent protein kinase and the responsible sequence domain. J Physiol, Vol.498, No.2, pp. 309-318. ISSN 0022-3751

Fuchs M, Hilfiker A, Kaminski K, Hilfiker-Kleiner D, Guener Z, Klein G, Podewski E, Schieffer B, Rose-John S \& Drexler H. (2003). Role of interleukin-6 for LV remodeling and survival after experimental myocardial infarction. FASEB J, Vol.17, No.4, pp. 2118-2120. ISSN 0892-6638

Fukuda K, Davies SS, Nakajima T, Ong BH, Kupershmidt S, Fessel J, Amarnath V, Anderson ME, Boyden PA, Viswanathan PC, Roberts LJ 2nd \& Balser JR. (2005). Oxidative mediated lipid peroxidation recapitulates proarrhythmic effects on cardiac sodium channels. Circ Res, Vol.97, No.12, pp. 1262-1269. ISSN 0009-7330

Gao L, Wang W, Li YL, Schultz HD, Liu D, Cornish KG \& Zucker IH. (2005). Simvastatin therapy normalizes sympathetic neural control in experimental heart failure: roles of angiotensin II type 1 receptors and $\mathrm{NAD}(\mathrm{P}) \mathrm{H}$ oxidase. Circulation, Vol.112, No.12, pp. 1763-1770. ISSN 0009-7322

Garcia-Dorado D, Inserte J, Ruiz-Meana M, González MA, Solares J, Juliá M, Barrabés JA \& Soler-Soler J. (1997). Gap junction uncoupler heptanol prevents cell-to-cell progression of hypercontracture and limits necrosis during myocardial reperfusion. Circulation, Vol.96, No.10, pp. 3579-3586. ISSN 0009-7322

Garcia-Dorado D, Rogriguez-Sinovas A \& Ruiz-Meana M. (2004). Gap junction-mediated spread of cell injury and death during myocardial ischemia-reperfusion. Cardiovas Res, Vol.61, No.3 pp. 386-410. ISSN 0008-6363 
Gardner PI, Ursell PC, Fenoglio JJ Jr \& Wit AL. (1985). Electrophysiologic and anatomic basis for fractionated electrograms recorded from healed myocardial infarcts. Circulation, Vol.72, No.3, pp. 596-611. ISSN 0009-7322

Gidh-Jain M, Huang B, Jain P \& el-Sherif N. (1996). Differential expression of voltage-gated $\mathrm{K}^{+}$channel genes in left ventricular remodeled myocardium after experimental myocardial infarction. Circ Res, Vol.79, No.4, pp. 669-675. ISSN 0009-7330

Goubaeva F, Mikami M, Giardina S, Ding B, Abe J \& Yang J. (2007). Cardiac mitochondrial connexin 43 regulates apoptosis. Biochem Biophys Res Commun, Vol.352, No.1, pp. 97-103. ISSN 0006-291X

Gourdie RG, Green CR \& Severs NJ. (1991). Gap junction distribution in adult mammalian myocardium revealed by an antipeptide antibody and laser scanning confocal microscopy. J Cell Sci, Vol.99, No.1, pp. 41-55. ISSN 0021-9533

Guerrero PA, Schuessler RB, Davis LM, Beyer EC, Johnson CM, Yamada KA \& Saffitz JE. (1997). Slow ventricular conduction in mice heterozygous for a connexin 43 null mutation. J Clin Invest, Vol.99, No.8, pp. 1991-1998. ISSN 0021-9738

Gulbenkian S, Saetrum Opgaard O, Ekman R, Costa Andrade N, Wharton J, Polak JM, Queiroz e Melo J \& Edvinsson L. (1993). Peptidergic innervation of human epicardial coronary arteries. Circ Res, Vol.73, No.3, pp. 579-588. ISSN 0009-7330

Gutstein DE, Morley GE, Tamaddon H, Vaidya D, Schneider MD, Chen J, Chien KR, Stuhlmann H \& Fishman GI. (2001). Conduction slowing and sudden arrhythmic death in mice with cardiac-restricted inactivation of connexin43. Circ Res, Vol.88, No.3, pp. 333-339. ISSN 0009-7330

Gutstein DE, Danik SB, Lewitton S, France D, Liu F, Chen FL, Zhang J, Ghodsi N, Morley GE \& Fishman GI. (2005). Focal gap junction uncoupling and spontaneous ventricular ectopy. Am J Physiol Heart Circ Physiol, Vol.289, No.3, pp. H1091-8. ISSN 0363-6135

Gwechenberger M, Mendoza LH, Youker KA, Frangogiannis NG, Smith CW, Michael LH \& Entman ML. (1999). Cardiac myocytes produce interleukin-6 in culture and in viable border zone of reperfused infarctions. Circulation, Vol.99, No.4, pp. 546-551. ISSN 0009-7322

Hagège AA, Marolleau JP, Vilquin JT, Alhéritière A, Peyrard S, Duboc D, Abergel E, Messas E, Mousseaux E, Schwartz K, Desnos M \& Menasché P (2006). Skeletal myoblast transplantation in ischemic heart failure: long-term follow-up of the first phase I cohort of patients. Circulation, Vol.114, No. (1 Suppl), pp. 1108-13. ISSN 0009-7322

Hagemeijer F. (1993). Calcium sensitization with pimobendan: pharmacology, haemodynamic improvement, sudden death in patients with chronic congestive heart failure. Eur Heart J, Vol.14, No.4, pp. 551-566. ISSN 0195-668X

Harris AL. (2001). Emerging issues of connexin channels: biophysics fills the gap. Q Rev Biophys, Vol.34, No.3, pp. 325-472. ISSN 0033-5835

Haugan K, Olsen KB, Hartvig L, Petersen JS, Holstein-Rathlou NH, Hennan JK \& NlelsenI MS. (2005). The antiarrhythmic peptide analog ZP123 prevents atrial conduction slowing during metabolic stress. J Cardiovasc Electrophysiol, Vol.16, No.5, pp. 537545. ISSN 1045-3873

HE Yan, ZENG Zhi-yu, ZHONG Guo-qiang, LI Jin-yi, LI Wei-ke \& LI Wei. (2009). Cx43 in mitochondria participates in the protection for heptanol preconditioning on 
myocardial ischemia/reperfusion injury of rabbits. Chinese Pharmacological Bulletin, Vol.25, No.12, pp. 1660-1665. ISSN 1001-1978

HE Yan, ZHONG Guo-qiang, ZENG Zhi-yu, LI Wei-ke, LI Wei \& LI Jin-yi. (2010). Effects of heptanol preconditioning on structure,function and $\mathrm{C} \times 43$ content of mitochondria in rabbit model of myocardial ischemia/reperfusion injury. Chinese Journal of Pathophysiology, Vol.26, No.3, pp. 461-465. ISSN 1000-4718

Henkel DM, Witt BJ, Gersh BJ, Jacobsen SJ, Weston SA, Meverden RA \& Roger VL. (2006). Ventricular arrhythmias after acute myocardial infarction: a 20-year community study. Am. Heart J, Vol.151, No.4, pp. 806-812. ISSN 0002-8703

Herbert E \& Chahine M. (2006). Clinical aspects and physiopathology of Brugada syndrome: review of current concepts. Can J Physiol Pharmacol, Vol.84, No.8-9, pp. 795-802. ISSN 0008-4212

Hille B. (1978). Ionic channels in excitable membranes. Current problems and biophysical approaches. Biophys J. Vol.22, No.2, pp. 283-94. ISSN 0006-3495

Huang B, El-Sherif T, Gidh-Jain M, Qin D \& El-Sherif N. (2001a). Alterations of sodium channel kinetics and gene expression in the postinfarction remodeled myocardium. J Cardiovasc Electrophysiol, Vol.12, No.2, pp. 218-225. ISSN 1045-3873

Huang B, Qin D \& El-Sherif N. (2001b). Spatial alterations of Kv channels expression and $\mathrm{K}(+)$ currents in post-myocardial infarction remodeled rat heart. Cardiovasc Res, Vol.52, No.2, pp. 246-254. ISSN 0008-6363

Ieda M, Kanazawa H, Kimura K, Hattori F, Ieda Y, Taniguchi M, Lee JK, Matsumura K, Tomita Y, Miyoshi S, Shimoda K, Makino S, Sano M, Kodama I, Ogawa S \& Fukuda K. (2007). Sema3a maintains normal heart rhythm through sympathetic innervation patterning. Nat Med, Vol.13, No.5, pp. 604-612. ISSN 1078-8956

Issa ZF, Ujhelyi MR, Hildebrand KR, Zhou X, Rosenberger J, Groh WJ, Miller JM \& Zipes DP. (2005). Intrathecal clonidine reduces the incidence of ischemiaprovoked ventricular arrhythmias in a canine postinfarction heart failure model. Heart Rhythm, Vol.2, No.10, pp. 1122-1127. ISSN 1547-5271

Janse MJ \& Wit AL. (1989). Electrophysiological mechanisms of ventricular arrhythmias resulting from myocardial ischemia and infarction. Physiol Rev, Vol.69, No.4, pp. 1049-1069. ISSN 0031-9333

Janssens S, Dubois C, Bogaert J, Theunissen K, Deroose C, Desmet W, Kalantzi M, Herbots L, Sinnaeve P, Dens J, Maertens J, Rademakers F, Dymarkowski S, Gheysens O, Van Cleemput J, Bormans G, Nuyts J, Belmans A, Mortelmans L, Boogaerts M \& Van de Werf F. (2006). Autologous bone marrow-derived stem-cell transfer in patients with ST-segment elevation myocardial infarction: double-blind, randomised controlled trial. Lancet, Vol.367, No.9505, pp. 113-121. ISSN 0140-6736

Jiang M, Cabo C, Yao J, Boyden PA \& Tseng G. (2000). Delayed rectifier $\mathrm{K}^{+}$currents have reduced amplitudes and altered kinetics in myocytes from infarcted canine ventricle. Cardiovasc Res, Vol.48, No.1, pp. 34-43. ISSN 0008-6363

Jin H, Lyon AR \& Akar FG. (2008). Arrhythmia mechanisms in the failing heart. Pacing Clin Electrophysiol, Vol.31, No.8, pp. 1048-56. ISSN 0147-8389

Kaplan DR \& Miller FD. (2003). Axon growth inhibition: signals from the p75 neurotrophin receptor. Nat Neurosci, Vol.6, No.5 pp. 435-436. ISSN 1097-6256

Kaprielian R, Sah R, Nguyen T, Wickenden AD \& Backx PH. (2002). Myocardial infarction in rat eliminates regional heterogeneity of $\mathrm{AP}$ profiles, $\mathrm{I}_{\mathrm{to}} \mathrm{K}^{+}$currents, $\left[\mathrm{Ca}^{2+}\right]_{\mathrm{i}}$ 
transients. Am J Physiol Heart Circ Physiol, Vol.283, No.3, pp. H1157-H1168. ISSN 0363-6135

Kaprielian RR, Gunning M, Dupont E, Sheppard MN, Rothery SM, Underwood R, Pennell DJ, Fox K, Pepper J, Poole-Wilson PA \& Severs NJ. (1998). Down-regulation of immunodetectable connexin 43 and decreased gap junction size in the pathogenesis of chronic hibernation in the human left ventricle. Circulation, Vol.97, No.7, pp. 651660. ISSN 0009-7322

Kim YK, Kim SJ, Kramer CM, Yatani A, Takagi G, Mankad S, Szigeti GP, Singh D, Bishop SP, Shannon RP, Vatner DE \& Vatner SF. (2002). Altered excitation-contraction coupling in myocytes from remodeled myocardium after chronic myocardial infarction. J Mol Cell Cardiol, Vol.34, No.1, pp. 63-73. ISSN 0022-2828

Kleber AG \& Rudy Y. (2004). Basic mechanisms of cardiac impulse propagation and associated arrhythmias. Physiol Rev, Vol.84, No.2, pp. 431-488. ISSN 0031-9333

Kostin S, Rieger M, Dammer S, Hein S, Richter M, Klövekorn WP, Bauer EP \& Schaper J. (2003). Gap junction remodeling and altered connexin43 expression in the failing human heart. Mol Cell Biochem, Vol.242, No.1, pp. 135-144. ISSN 0300-8177

Koval M, Geist ST, Westphale EM, Kemendy EM, Civitelli R, Beyer EC \& Steinberg TH (1995). Transfected connexin 45 alters gap junction permeability in cells expressing endogenous connexin 43. J Cell Biol, Vol.130, No.4, pp. 987-995. ISSN 0021-9525

Kuruvilla R, Zweifel LS, Glebova NO, Lonze BE, Valdez G, Ye H \& Ginty DD. (2004). A neurotrophin signaling cascade coordinates sympathetic neuron development through differential control of TrkA trafficking and retrograde signaling. Cell, Vol.118, No.2, pp. 243-255. ISSN 0092-8674

Laflamme, M. A. \& Murry, C. E. (2005). Regenerating the heart. Nature Biotechnol, Vol.23, No.7, pp. 845-856. ISSN 1087-0156

Laing JG, Beyer EC. (2000). Degradation of gap junctions and connexins. In: Gap junctions. Molecular basis of cell communication in health and disease. Peracchia C, pp. 23-41, Academic Press, ISBN 0-12-153349-2, San Diego

Lampe PD, Cooper CD, King TJ \& Burt JM. (2006). Analysis of Connexin43 phosphorylated at S325, S328 and S330 in normoxic and ischemic heart. J Cell Sci, Vol.119, No16, pp. 3435-3442. ISSN 0021-9533

Leblanc N \& Hume JR. (1990). Sodium current-induced release of calcium from cardiac sarcoplasmic reticulum. Science, Vol.248, No.4953, pp. 372-376. ISSN 0036-8075

Leobon B, Garcin I, Menasche P, Vilquin JT, Audinat E \& Charpak S. (2003). Myoblasts transplanted into rat infarcted myocardium are functionally isolated from their host. Proc. Natl Acad. Sci, Vol.100, No.13, pp. 7808-7811. ISSN 0027-8424

Lerner DL, Yamada KA, Schuessler RB \& Saffitz JE. (2000). Accelerated onset and increased incidence of ventricular arrhythmias induced by ischemia in Cx43-deficient mice. Circulation, Vol.101, No.5, pp. 547-552. ISSN 0009-7322

LI Jinyi, ZHONG Guoqiang, HE Yan \& LING Yun. (2009a). Cardiac Connexin 43 and Ischemic Cardioprotection. South China Journal of Cardiovascular Diseases, Vol.10, No.2, pp. 97-105. ISSN 1007-9688

Li Jin-yi, Zhong Guo-qiang, He Yan, Wen Li-na, Ke Hong-hong, Wei Zhuo, Deng Yan \& Wu Zhi-fu. (2009b). Effects of allogenic bone marrow mesenchymal stem cell transplantation on electrophysiological abnormality and left ventricular 
remodeling in rats with myocardial infarction. Journal of Clinical Rehabilitative Tissue Engineering Research, Vol.13, No.27, pp. 5211-5216. ISSN 1671-5926

LI Jin-yi, ZHONG Guo-qiang, WEI Zhuo, XU Wei-yan, KE Hong-hong, NING Zong \& WU ZHI-fu. (2009c). Establishment of a rat model of myocardial infarction and the postinfarction changes in electrophysiology and lef ventricular function. Acta laboratorium animalis scientia sinica, Vol.17, No.6, pp. 419-423. ISSN 1005-4847

LI Jinyi, ZHONG Guoqiang, KE Honghong, HE Yan, WEN Lina, WEI Zhuo \& ZHAO Yanmei. (2010). Transplantation of allogenic mesenchymal stem cells up-regulates connexin 43 expression in rats with myocardial infarction. Basic $\mathcal{E}$ Clinical Medicine, Vol.30, No.4, pp. 337-342. ISSN 1001-6325

Li W, Knowlton D, Van Winkle DM \& Habecker BA. (2004). Infarction alters both the distribution and noradrenergic properties of cardiac sympathetic neurons. Am J Physiol Heart Circ Physiol, Vol.286, No.6, pp. H2229-H2236. ISSN 0363-6135

Li X, Huang CX, Jiang H, Cao F \& Wang T. (2005). The beta-adrenergic blocker carvedilol restores L-type calcium current in a myocardial infarction model of rabbit. Chin Med J, Vol.118, No.5, pp. 377-382. ISSN 0366-6999

Li Y, Xue Q, Ma J, Zhang CT, Qiu P, Wang L, Gao W, Cheng R, Lu ZY \& Wang SW. (2004). Effects of imidapril on heterogeneity of action potential and calcium current of ventricular myocytes in infarcted rabbits. Acta Pharmacol Sin, Vol.25, No.11, pp. 1458-1463. ISSN 1671-4083

Litwin SE, Zhang D \& Bridge JH. (2000). Dyssynchronous $\mathrm{Ca}\left({ }^{2+}\right)$ sparks in myocytes from infarcted hearts. Circ Res, Vol.87, No.11, pp. 1040-1047. ISSN 0009-7330

Liu N, Niu H, Li Y, Zhang C, Zhou Q, Ruan Y, Pu J \& Lu Z. (2004). The changes of potassium currents in rabbit ventricle with healed myocardial infarction. $J$ Huazhong Univ Sci Technolog Med Sci, Vol.24, No.2, pp. 128-131. ISSN 1672-0733

Long JB, Jay SM, Segal SS \& Madri JA. (2009). VEGF-A and semaphorin3A: modulators of vascular sympathetic innervation. Dev Biol, Vol.334, No.1, pp. 119-132. ISSN 00121606

Lorentz CU, Alston EN, Belcik T, Lindner JR, Giraud GD \& Habecker BA. (2010). Heterogeneous ventricular sympathetic innervation, altered b-adrenergic receptor expression, and rhythm instability in mice lacking the p75 neurotrophin receptor. Am J Physiol Heart Circ Physiol, Vol.298, No.6, pp. H1652-H1660. ISSN 0363-6135

Lubbe WF, Podzuweit T \& Opie LH. (1992). Potential arrhythmogenic role of cyclic adenosine monophosphate (AMP) and cytosolic calcium overload: implications for prophylactic effects of beta-blockers in myocardial infarction and proarrhythmic effects of phosphodiesterase inhibitors. J Am Coll Cardiol, Vol.19, No.7, pp. 16221633. ISSN 0735-1097

Lue WM \& Boyden PA. (1992). Abnormal electrical properties of myocytes from chronically infarcted canine heart. Alterations in Vmax and the transient outward current. Circulation, Vol.85, No.3, pp. 1175-1188. ISSN 0009-7322

Luisi AJ Jr, Fallavollita JA, Suzuki G \& Canty JM Jr. (2002). Spatial inhomogeneity of sympathetic nerve function in hibernating myocardium. Circulation, Vol.106, No.7, pp. 779-781. ISSN 0009-7322

Mahajan A, Moore J, Cesario DA \& Shivkumar K. (2005). Use of thoracic epidural anesthesia for management of electrical storm: a case report. Heart Rhythm, Vol.2, No.12, pp. 1359-1362. ISSN 1547-5271 
Maltsev VA, Sabbab HN \& Undrovinas AI. (2002). Down-regulation of sodium current in chronic heart failure: effect of long-term therapy with carvedilol. Cell Mol Life Sci, Vol.59, No.9, pp. 1561-1568. ISSN 1420-682X

Marmar Vaseghi \& Kalyanam Shivkumar. (2008). The Role of the Autonomic Nervous System in Sudden Cardiac Death. Prog Cardiovasc Dis, Vol.50, No.6, pp. 404-419. ISSN 0033-0620

Martinez AD, Hayrapetyan V, Moreno AP \& Beyer EC: (2002). Connexin 43 and connexin 45 form heteromeric gap junction channels in which individual components determine permeability and regulation. Circ Res, Vol.90, No.10, pp. 1100-1107. ISSN 0009-7330

Michael G, Xiao L, Qi XY, Dobrev D \& Nattel S. (2009). Remodelling of cardiac repolarization: how homeostatic responses can lead to arrhythmogenesis. Cardiovasc Res, Vol.81, No.3, pp. 491-9. ISSN 0008-6363

Moreno AP, Chanson M, Elenes S, Anumonwo J, Scerri I, Gu H, Taffet SM \& Delmar M. (2002a). Role of the carboxyl terminal of connexin43 in transjunctional fast voltage gating. Circ Res, Vol.90, No.4, pp. 450-7. ISSN 0009-7330

Moreno AP, Zhong G, Hayrapetyan V. (2002b). Heteromultimeric gap junction channels: a connection with cardiac physiology and pathology. In: Heart Cell Coupling and Impulse Propagation in Health and Disease-Basic Science for the Cardiologist, WC. De Mello, M. Janse, pp. 89-108. Kluwer Academic Publishers. ISBN 1-4020-7182-5, Norwell.

Moreno AP, Hayrapetyan V, Zhong G. (2004). Homomeric and Heteromeric Gap Junctions. In: Cardiac electrophysiololgy from cell to bedside. Douglas P.Zipes and Jose Jalife. pp. 120-126, W.B Saunders Company, ISBN 0-7216-0323-8, Philadelphia

Murry CE, Soonpaa MH, Reinecke H, Nakajima H, Nakajima HO, Rubart M, Pasumarthi KB, Virag JI, Bartelmez SH, Poppa V, Bradford G, Dowell JD, Williams DA \& Field LJ. (2004). Haematopoietic stem cells do not transdifferentiate into cardiac myocytes in myocardial infarcts. Nature, Vol.428, No.6983, pp. 664-668. ISSN 00280836

Murry CE, Field LJ \& Menasche P. (2005). Cell-based cardiac repair: reflections at the 10year point. Circulation, Vol.112, No.20, pp. 3174-3183. ISSN 0009-7322

Nademanee K, Taylor R, Bailey WE, Rieders DE \& Kosar EM. (2000). Treating electrical storm: sympathetic blockade versus advanced cardiac life support-guided therapy. Circulation, Vol.102, No.7, pp. 742-747. ISSN 0009-7322

Nattel S \& Carlsson L. (2006). Innovative approaches to anti-arrhythmic drug therapy. Nat Rev Drug Discov, Vol.5, No.12, pp. 1034-1049. ISSN 1474-1776

Nattel S, Maguy A, Le Bouter S, Yeh YH. (2007). Arrhythmogenic ion-channel remodeling in the heart: heart failure, myocardial infarction, and atrial fibrillation. Physiol Rev. Vol.87, No.2, pp. 425-56. ISSN 0031-9333

Nerbonne JM \& Kass RS. (2005). Molecular physiology of cardiac repolarization. Physiol Rev, Vol.85, No.4, pp. 1205-1253. ISSN 0031-9333

Nian M, Lee P, Khaper N \& Liu P. (2004). Inflammatory cytokines and postmyocardial infarction remodeling. Circ Res, Vol.94, No.12, pp. 1543-1553. ISSN 0009-7330

Noda M, Shimizu S, Tanabe T, Takai T, Kayano T, Ikeda T, Takahashi H, Nakayama H, Kanaoke Y, Minamino N, Kangawa R, Matsuo H, Raftery MA, Hirose T, Inayama S, Hayashida H, Miyata T \& Numa S. (1984). Primary structure of electrophorus 
electricus sodium channel deduced from cDNA sequence. Nature, Vol.312, No.5990, pp. 121-127. ISSN 0028-0836

Nori SL, Gaudino M, Alessandrini F, Bronzetti E \& Santarelli P. (1995). Immunohistochemical evidence for sympathetic denervation and reinnervation after necrotic injury in rat myocardium. Cell Mol Biol, Vol.41, No.6, pp. 799-807. ISSN 0145-5680

Nuss HB, Marbán E \& Johns DC. (1999). Overexpression of a human potassium channel suppresses cardiac hyperexcitability in rabbit ventricular myocytes. J Clin Invest, Vol.103, No.6, pp. 889. ISSN 0021-9738

Oh YS, Jong AY, Kim DT, Li H, Wang C, Zemljic-Harpf A, Ross RS, Fishbein MC, Chen PS \& Chen LS. (2006). Spatial distribution of nerve sprouting after myocardial infarction in mice. Heart Rhythm, Vol.3, No.6, pp. 728-736. ISSN 1547-5271

Oki T, Fukuda N, Kawano T, Iuchi A, Tabata T, Manabe K, Kageji Y, Sasaki M, Yamada H \& Ito S. (1995). Histopathologic studies of innervation of normal and prolapsed human mitral valves. J Heart Valve Dis, Vol.4, No.5, pp. 496-502. ISSN 0966-8519

Patlak JB \& Ortiz M. (1985). Slow currents through single sodium channels of adult rat heart. J Gen Physiol, Vol.86, No.1, pp. 89-104. ISSN 0022-1295

Perrier E, Kerfant BG, Lalevee N, Bideaux P, Rossier MF, Richard S, Gomez AM \& Benitah JP. (2004). Mineralocorticoid receptor antagonism prevents the electrical remodeling that precedes cellular hypertrophy after myocardial infarction. Circulation, Vol.110, No.7, pp. 776-783. ISSN 0009-7322

Peters NS, Coromilas J, Severs NJ \& Wit AL. (1997). Disturbed connexin43 gap junction distribution correlates with the location of reentrant circuits in the epicardial border zone of healing canine infarcts that cause ventricular tachycardia. Circulation, Vol.95, No.4, pp. 988-996. ISSN 0009-7322

Pinto JM, Yuan F, Wasserlauf BJ, Bassett AL \& Myerburg RJ. (1997). Regional gradation of Ltype calcium currents in the feline heart with a healed myocardial infarct. $J$ Cardiovasc Electrophysiol, Vol.8, No.5, pp. 548-560. ISSN 1045-3873

Pinto JM \& Boyden PA. (1998). Reduced inward rectifying and increased E-4031-sensitive K_ current density in arrhythmogenic subendocardial Purkinje myocytes from the infarcted heart. J Cardiovasc Electrophysiol, Vol.9, No.3, pp. 299-311. ISSN 1045-3873

$\mathrm{Pu}$ J \& Boyden PA. (1997). Alterations of $\mathrm{Na}^{+}$currents in myocytes from epicardial border zone of the infarcted heart. A possible ionic mechanism for reduced excitability and postrepolarization refractoriness. Circ Res, Vol.81, No.1, pp. 110-119. ISSN 00097330

$\mathrm{Pu}$ J, Balser JR \& Boyden PA. (1998). Lidocaine action on $\mathrm{Na}^{+}$currents in ventricular myocytes from the epicardial border zone of the infarcted heart. Circ Res, Vol. 83, No.4, pp. 431-440. ISSN 0009-7330

Pu J, Ruffy F \& Boyden PA. (1999). Effects of Bay Y 5959 on $\mathrm{Ca}^{2+}$ currents and intracellular $\mathrm{Ca}^{2+}$ in cells that have survived in the epicardial border of the infarcted canine heart. J Cardiovasc Pharmacol, Vol.33, No.6, pp. 929-937. ISSN 0160-2446

$\mathrm{Pu}$ J, Robinson RB \& Boyden PA. (2000). Abnormalities in Ca(i) handling in myocytes that survive in the infarcted heart are not just due to alterations in repolarization. $J \mathrm{Mol}$ Cell Cardiol, Vol.32, No.8, pp. 1509-1523. ISSN 0022-2828 
Qi X, Varma P, Newman D \& Dorian P. (2001). Gap junction blockers decrease defibrillation thresholds with out changes in ventricular refractoriness in isolated rabbit hearts. Circulation, Vol.104, No.13, pp. 1544-1549. ISSN 0009-7322

Qin D, Zhang ZH, Caref EB, Boutjdir M, Jain P \& el-Sherif N. (1996). Cellular and ionic basis of arrhythmias in postinfarction remodeled ventricular myocardium. Circ Res , Vol.79, No.3, pp. 461-473. ISSN 0009-7330

Ranger S \& Nattel S. (1995). Determinants and mechanisms of flecainideinduced promotion of ventricular tachycardia in anesthetized dogs. Circulation, Vol.92, No.5, pp. 13001311. ISSN 0009-7322

Rautaharju PM, Zhou SH, Wong S, Calhoun HP, Berenson GS, Prineas R \& Davignon A. (1992). Sex differences in the evolution of the electrocardiographic QT interval with age. Can J Cardiol, Vol.8, No.7, pp. 690-695. ISSN 0828-282X

Reinecke H, Poppa V \& Murry CE. (2002). Skeletal muscle stem cells do not transdifferentiate into cardiomyocytes after cardiac grafting. J. Mol. Cell. Cardiol, Vol.34, No.2, pp. 241-249. ISSN 0022-2828

Ren C, Wang F, Li G, Jiao Q, Bai J, Yu D, Hao W, Wang R \& Cao JM. (2008). Nerve sprouting suppresses myocardial I(to) and I(K1) channels and increases severity to ventricular fibrillation in rat. Auton Neurosci, Vol.144, No.1-2, pp. 22-9. ISSN 1566-0702

Restivo M, Gough WB \& el-Sherif N. (1990). Ventricular arrhythmias in the subacute myocardial infarction period. High-resolution activation and refractory patterns of reentrant rhythms. Circ Res, Vol.66, No.5, pp. 1310-1327. ISSN 0009-7330

Rodriguez-Sinovas A, Boengler K, Cabestrero A, Gres P, Morente M, Ruiz-Meana M, Konietzka I, Miró E, Totzeck A, Heusch G, Schulz R \& Garcia-Dorado D. (2006). Translocation of Connexin 43 to the Inner Mitochondrial Membrane of Cardiomyocytes Through the Heat Shock Protein 90-Dependent TOM Pathway and Its Importance for Card ioprotection. Circ Res, Vol.99, No.1, pp. 93-101. ISSN 00097330

Roell W, Lewalter T, Sasse P, Tallini YN, Choi BR, Breitbach M, Doran R, Becher UM, Hwang SM, Bostani T, von Maltzahn J, Hofmann A, Reining S, Eiberger B, Gabris B, Pfeifer A, Welz A, Willecke K, Salama G, Schrickel JW, Kotlikoff MI \& Fleischmann BK. (2007). Engraftment of connexin 43-expressing cells prevents postinfarct arrhythmia. Nature, Vol.450, No.7171, pp. 819-824. ISSN 0028-0836

Rubart M \& Zipes DP. (2005). Mechanisms of sudden cardiac death. J Clin Invest, Vol.115, No.9, pp. 2305-2315. ISSN 0021-9738

Saltman AE, Aksehirli TO, Valiunas V, Gaudette GR, Matsuyama N, Brink P \& Krukenkamp IB. (2002). Gap junction uncoupling protects the heart against ischemia. J Thorac Cardiovasc Surg, Vol.124, No.2, pp. 371-376. ISSN 0022-5223

Salameh A \& Dhein S. (2005). Pharmacology of gap junctions. New pharmacological targets for treatment of arrhythmia, seizure and cancer? Biochim Biophys Acta, Vol.1719, No.1-2, pp. 36-58. ISSN 0005-2736

Sasano T, McDonald AD, Kikuchi K \& Donahue JK. (2006). Molecular ablation of ventricular tachycardia after myocardial infarction. Nat Med, Vol.12, No.11, pp. 1256. ISSN 1078-8956 
Schulz R, Boengler K, Totzeck A, Luo Y, Garcia-Dorado D \& Heusch G. (2007). Connexin 43 in ischemic pre- and postconditioning. Heart Fail Rev, Vol.12, No.3-4, pp. 261-266. ISSN 1382-4147

Schwartz PJ \& Stone HL. (1980). Left stellectomy in the prevention of ventricular fibrillation caused by acute myocardial ischemia in conscious dogs with anterior myocardial infarction. Circulation, Vol.62, No.6, pp. 1256-1265. ISSN 0009-7322

Schwartz PJ, Motolese M, Pollavini G, Lotto A, Ruberti U, Trazzi R, Bartorelli C \& Zanchetti A. (1992). Italian Sudden Death Prevention Group. Prevention of sudden cardiac death after a first myocardial infarction by pharmacologic or surgical antiadrenergic interventions. J Cardiovasc Electrophysiol, Vol.3, No.1, pp. 2-16. ISSN 1045-3873

Sebbag L, Verbinski SG, Reimer KA \& Jennings RB. (2003). Protection of ischemic myocardium in dogs using intracoronary 2, 3-butanedione monoxime (BDM). J Mol Cell Cardiol, Vol.35, No.2, pp. 165-176. ISSN 0022-2828

Severs NJ, (1989). Constituent cells of the heart and isolated cell models in cardiovascular research. In: Isolated Adult Cardiomyocytes: Structure and metabolism, Piper HM, Isenberg G, pp. 3-41, CRC Press, Boca Raton.

Severs NJ. (1990). The cardiac gap junction and intercalated disc. Int J Cardiol, Vol.26, No.2, pp. 137-73. ISSN 0167-5273

Severs NJ, Gourdie RG, Harfst E, Peters NS \& Green CR. (1993). Intercellular junctions and the application of microscopical techniques: the cardiac gap junction as a case model. J Microsc, Vol.169, No.3, pp. 299-328. ISSN 0022-2720

Severs NJ, Rothery S, Dupont E, Coppen SR, Yeh HI, Ko YS, Matsushita T, Kaba R \& Halliday D. (2001). Immunocytochemical analysis of connexin expression in the healthy and diseased cardiovascular system. Microsc Res Tech, Vol.52, No.3, pp. 301-22. ISSN 1059-910X

Severs NJ, Coppen SR, Dupont E, Yeh HI, Ko YS, Matsushita T. (2004). Gap junction alterations in human cardiac disease. Cardiovasc Res. Vol.62, No.2, pp. 368-77. ISSN 0008-6363

Severs NJ, Bruce AF, Dupont E \& Rothery S. (2008). Remodelling of gap junctions and connexin expression in diseased myocardium. Cardiovasc Res, Vol.80, No.1, pp. 9-19. ISSN 0008-6363

Shaw RM \& Rudy Y. (1997). Ionic mechanisms of propagation in cardiac tissue. Roles of the sodium and L-type calcium currents during reduced excitability and decreased gap junction coupling. Circ Res, Vol.81, No.5, pp. 727-741. ISSN 0009-7330

Smith JH, Green CR, Peters NS, Rothery S \& Severs NJ. (1991). Altered patterns of gap junction distribution in ischemic heart disease. An immunohistochemical study of human myocardium using laser scanning confocal microscopy. Am J Pathol, Vol.139, No.4, pp. 801-821. ISSN 0002-9440

Sohl G \& Willecke K. (2004). Gap junctions and the connexin protein family. Cardiovasc Res, Vol.62, No.2, pp. 228-232. ISSN 0008-6363

Solomon SD, Zelenkofske S, McMurray JJ, Finn PV, Velazquez E, Ertl G, Harsanyi A, Rouleau JL, Maggioni A, Kober L, White H, Van de Werf F, Pieper K, Califf RM \& Pfeffer MA. (2005). Sudden death in patients with myocardial infarction and left ventricular dysfunction, heart failure, or both. $N$ Eng J Med, Vol.352, No.25, pp. 2581-2588. ISSN 0028-4793 
Sosinsky G. (2000). Gap junction structure: new structures and new insights. In: Gap junctions. Molecular basis of cell communication in health and disease. Peracchia C, pp. 122, Academic Press,: ISBN 0-12-153349-2, San Diego

Spear JF, Michelson EL, Spielman SR \& Moore EN. (1977). The origin of ventricular arrhythmias 24 hours following experimental anterior septal coronary artery occlusion. Circulation, Vol.55, No.6, pp. 844-852. ISSN 0009-7322

Spear JF, Horowitz LN, Hodess AB, MacVaugh H 3rd \& Moore EN. (1979). Cellular electrophysiology of human myocardial infarction. 1. Abnormalities of cellular activation. Circulation, Vol.59, No.2, pp. 247-256. ISSN 0009-7322

Takamatsu T. (2008). Arrhythmogenic substrates in myocardial infarct. Pathol Int, Vol.58, No.9, pp. 533-43. ISSN 1320-5463

Ursell PC, Gardner PI, Albala A, Fenoglio Jr. JJ \& Wit AL. (1985). Structural and electrophysiological changes in the epicardial border zone of canine myocardial infarcts during infarct healing. Circ Res, Vol.56, No.3, pp. 436-451. ISSN 0009-7330

Valiunas V, Doronin S, Valiuniene L, Potapova I, Zuckerman J, Walcott B, Robinson RB, Rosen MR, Brink PR \& Cohen IS. (2004). Human mesenchymal stem cells make cardiac connexins and form functional gap junctions.J Physiol, Vol.555, No.3, pp. 617-626. ISSN 0022-3751

Van Veen AA, van Rijen HV \& Opthof T. (2001). Cardiac gap junction channels: modulation of expression and channel properties. Cardiovasc Res, Vol.51, No2, pp. 217-29. ISSN 0008-6363

Vozzi C, Dupont E, Coppen SR, Yeh HI \& Severs NJ. (1999). Chamber-related differences in connexin expression in the human heart. J Mol Cell Cardiol, Vol.31, No5, pp. 9911003. ISSN 0022-2828

Vracko R, Thorning D \& Frederickson RG. (1990). Fate of nerve fibers in necrotic, healing, and healed rat myocardium. Lab Invest, Vol.63, No.4, pp. 490-501. ISSN 0023-6837

Vracko R, Thorning D \& Frederickson RG. (1991). Nerve fibers in human myocardial scars. Hum Pathol, Vol.22, No.2, pp. 138-146. ISSN 0046-8177

Waldo AL, Camm AJ, deRuyter H, Friedman PL, MacNeil DJ, Pauls JF, Pitt B, Pratt CM, Schwartz PJ \& Veltri EP. (1996). Effect of D-sotalol on mortality in patients with left ventricular dysfunction after recent and remote myocardial infarction. The SWORD Investigators survival with oral D-sotalol. Lancet, Vol.348, No.9019, pp. 7-12. ISSN 0140-6736

Wen H, Jiang H, Lu Z, Hu X, He B, Tang Q \& Huang C. (2010). Carvedilol ameliorates sympathetic nerve sprouting and electrical remodelling after myocardial infarction in rats. Biomedicine \& Pharmacotherapy, Vol.64, No.7, pp. 446-450. ISSN 0753-3322

Weng S, Lauven M, Schaefer T, Polontchouk L, Grover R \& Dhein S. (2002). Pharmacological modification of gap junction coupling by an antiarrhythmic peptide via protein kinase C activation. FASEB J, Vol.16, No.9, pp. 1114-6. ISSN 0892-6638

Wong RC, Pera MF \& Pébay A. (2008). Role of Gap Junctions in Embryonic and Somatic Stem Cells. Stem Cell Rev, Vol.4, No.4, pp. 283-292. ISSN 1550-8943

Xin P, Pan Y, Zhu W, Huang S, Wei M \& Chen C. (2010). Favorable effects of resveratrol on sympathetic neural remodeling in rats following myocardial infarction. European Journal of Pharmacology, Vol.649, No.1-3, pp. 293-300. ISSN 0014-2999

Xing D, Kjølbye AL, Nielsen MS, Petersen JS, Harlow KW, Holstein-Rathlou NH \& Martins JB. (2003). ZP123 increases gap junctional conductance and prevents reentrant 
ventricular tachycardia during myocardial ischemia in open chest dogs. J Cardiovasc Electrophysiol, Vol.14, No.5, pp. 510-20. ISSN 1045-3873

Yagi T \& Boyden PA. (2002). Protein tyrosine kinases and L-type $\mathrm{Ca}^{2+}$ currents in cells that have survived in epicardial border zone of canine infarcted heart. J Cardiovasc Pharmacol, Vol.40, No.5, pp. 669-677. ISSN 0160-2446

Yamada KA, Rogers JG, Sundset R, Steinberg TH \& Saffitz JE. (2003). Up-regulation of connexin45 in heart failure. J Cardiovasc Electrophysiol, Vol.14, No.11, pp. 1205-1212. ISSN 1045-3873

Yao JA, Hussain W, Patel P, Peters NS, Boyden PA \& Wit AL. (2003). Remodeling of gap junctional channel function in epicardial border zone of healing canine infarcts. Circ Res, Vol.92, No.4, pp. 437-443. ISSN 0009-7330

Yuan F, Pinto JM, Li Q, Wasserlauf BJ, Yang X, Bassett AL \& Myerburg RJ. (1999). Characteristics of $\mathrm{I}(\mathrm{K})$ and its response to quinidine in experimental healed myocardial infarction. J Cardiovasc Electrophysiol, Vol.10, No.6, pp. 844-854. ISSN 1045-3873

Yuan MJ, Huang CX, Tang YH, Wang X, Huang H, Chen YJ \& Wang T. (2009). A novel peptide ghrelin inhibits neural remodeling after myocardial infarction in rats. European Journal of Pharmacology, Vol.618, No.1-3, pp. 52-57. ISSN 0014-2999

Zhao Yan-mei, Zhong Guo-qiang, Li Jin-yi, He Yan, Ke Hong-hong \& Wang Dong-xu. (2009). mRNA expression of connectin 43 and connectin 45 following transplantation of allogenic bone marrow mesenchymal stem cells in rats with acute myocardial infarction. Journal of Clinical Rehabilitative Tissue Engineering Research, Vol.13, No.45, pp. 8895-8900. ISSN 1671-5926

Zhao Yan-mei, Zhong Guo-qiang, Ke Hong-hong \& Li Jin-yi. (2010). Effects of different conditions on rat bone marrow mesenchymal stem cells differentiating into cardiomyocytes in vitro. Basic \& Clinical Medicine, Vol.30, No.6, pp. 561-565. ISSN 1001-6325

Zhong G, Hayrapetyan V \& Moreno AP. (2002). The Formation of mono-heteromeric Cx43$\mathrm{C} \times 45 / 43$ gap junctions uncovers gating and selectivity properties of their channels. Biophysical Journal, Vol.82, No.1, pp. 633b. ISSN 0006-3495

Zhou S, Chen LS, Miyauchi Y, Miyauchi M, Kar S, Kangavari S, Fishbein MC, Sharifi B \& Chen PS. (2004). Mechanisms of cardiac nerve sprouting after myocardial infarction in dogs. Circ Res, Vol.95, No.1, pp. 76-83. ISSN 0009-7330

Zhou S, Jung BC, Tan AY, Trang VQ, Gholmieh G, Han SW, Lin SF, Fishbein MC, Chen PS, Chen LS. (2008). Spontaneous stellate ganglion nerve activity and ventricular arrhythmia in a canine model of sudden death. Heart Rhythm. Vol.5, No.1, pp. 1319. ISSN 1547-5271

Zipes DP. (1990). Influence of myocardial ischemia and infarction on autonomic innervation of heart. Circulation, Vol.82, No.4, pp. 95-105. ISSN 0009-7322. 


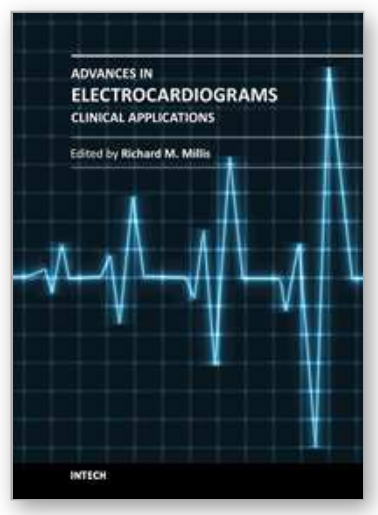

\author{
Advances in Electrocardiograms - Clinical Applications \\ Edited by PhD. Richard Millis
}

ISBN 978-953-307-902-8

Hard cover, 328 pages

Publisher InTech

Published online 25, January, 2012

Published in print edition January, 2012

Electrocardiograms have become one of the most important, and widely used medical tools for diagnosing diseases such as cardiac arrhythmias, conduction disorders, electrolyte imbalances, hypertension, coronary artery disease and myocardial infarction. This book reviews recent advancements in electrocardiography. The four sections of this volume, Cardiac Arrhythmias, Myocardial Infarction, Autonomic Dysregulation and Cardiotoxicology, provide comprehensive reviews of advancements in the clinical applications of electrocardiograms. This book is replete with diagrams, recordings, flow diagrams and algorithms which demonstrate the possible future direction for applying electrocardiography to evaluating the development and progression of cardiac diseases. The chapters in this book describe a number of unique features of electrocardiograms in adult and pediatric patient populations with predilections for cardiac arrhythmias and other electrical abnormalities associated with hypertension, coronary artery disease, myocardial infarction, sleep apnea syndromes, pericarditides, cardiomyopathies and cardiotoxicities, as well as innovative interpretations of electrocardiograms during exercise testing and electrical pacing.

\title{
How to reference
}

In order to correctly reference this scholarly work, feel free to copy and paste the following:

Guoqiang Zhong, Jinyi Li, Honghong Ke, Yan He, Weiyan Xu and Yanmei Zhao (2012). Mechanisms of Postinfarction Electrophysiological Abnormality: Sympathetic Neural Remodeling, Electrical Remodeling and Gap Junction Remodeling, Advances in Electrocardiograms - Clinical Applications, PhD. Richard Millis (Ed.), ISBN: 978-953-307-902-8, InTech, Available from: http://www.intechopen.com/books/advances-inelectrocardiograms-clinical-applications/mechanisms-of-postinfarction-electrophysiological-abnormalitysympathetic-neural-remodeling-electric

\section{INTECH}

open science | open minds

\author{
InTech Europe \\ University Campus STeP Ri \\ Slavka Krautzeka 83/A \\ 51000 Rijeka, Croatia \\ Phone: +385 (51) 770447 \\ Fax: +385 (51) 686166 \\ www.intechopen.com
}

\author{
InTech China \\ Unit 405, Office Block, Hotel Equatorial Shanghai \\ No.65, Yan An Road (West), Shanghai, 200040, China \\ 中国上海市延安西路65号上海国际贵都大饭店办公楼 405 单元 \\ Phone: +86-21-62489820 \\ Fax: +86-21-62489821
}


(C) 2012 The Author(s). Licensee IntechOpen. This is an open access article distributed under the terms of the Creative Commons Attribution 3.0 License, which permits unrestricted use, distribution, and reproduction in any medium, provided the original work is properly cited. 